\title{
Improving Wetland Characterization with Multi-Sensor, Multi-Temporal SAR and Optical/Infrared Data Fusion
}

\author{
Laura L. Bourgeau-Chavez, Kevin Riordan*, Richard B. Powell, \\ Nicole Miller** and Mitch Nowels ${ }^{* * *}$ \\ Michigan Technological University, Michigan Tech Research Institute, \\ 3600 Green Ct., Ste. 100, Ann Arbor, MI, USA \\ * Independent Researcher, 85B East Jefferson Rd. Pittsford, NY, USA \\ ** Radiance Technologies, Inc. Bldg 1103, Suite 210 Stennis Space Center MS, USA \\ *** 8700 SW 174th Street, Miami, FL, USA
}

\section{Introduction}

Wetlands provide habitat and food sources for wildlife, protect waterways, act as natural filtration systems, and serve major ecological roles in the overall health of our local, regional and global ecosystems. While wetlands serve such vital ecological functions, due to their limited capacity for adaptation wetland ecosystems are highly vulnerable to change, from both climatic (IPCC 2008) and anthropogenic sources. In the past, wetlands have been drained and converted to uplands at an alarming rate and the remaining wetlands are subject to a number of threats including eutrophication, climate change, invasive plant species, and the interaction between these stressors. Due to these vulnerabilities, there exists a need for policy and resource managers to have an operational strategy for monitoring the extent, composition, and vigor of wetlands at a synoptic scale. For regional areas, such as the coastal Great Lakes, Boreal Canada, or vast wetland complexes such as the Pantanal, Mesopotamian marshlands, or the Greater Everglades, cost-effective implementable methods are necessary. For fine scale studies, cost is generally less of an issue and the highest resolution data with the highest cost may be justified. In this chapter, we focus on methods for regional scale mapping and monitoring where the minimum mapping unit of interest is 5 acres, and thus use moderate resolution satellite imagery $(20-30 \mathrm{~m})$. The focus is on multi-sensor data fusion between SAR single channel and/or multi-channel data and Optical/IR sensor data. Case studies in the Great Lakes and Boreal peatlands demonstrate the advantages and widespread utilty of a hybrid SAR-Optical/IR approach.

While many definitions of wetlands exist, both scientific and legal, in essence wetlands are defined by: (1) the presence of water at, above, or near the ground surface; (2) hydric soils; and (3) vegetation species adapted to or tolerant of wet soil conditions. Remote sensing can 
be used to map and monitor two of the defining wetland features; vegetation type and surface water/wet soils.

Wetlands have historically been one of the most difficult ecosystems to classify using remotely sensed data. This difficulty is partially due to the high variability in wetland morphology. Wetlands can exist in many shapes and sizes, from open wet areas with sparse vegetative cover to densely forested areas with seasonal flooding. Vegetative cover ranges from low herbaceous, to shrubby, to forest.

Traditionally, optical data have been used to map wetlands along with other land cover and land use. However, due to the complexity of wetland ecosystems it would be beneficial to include a fusion of sensors, operating in different frequencies (thermal, optical, lidar, radar, infrared) that measure various aspects of wetlands for improved mapping accuracy. Optical and infrared data are well suited to mapping vegetation ecosystem types and condition. Complementary to Optical/IR, Synthetic Aperture Radar (SAR) data are capable of detecting flooding beneath a vegetation canopy, monitoring water levels and soil moisture, and also for distinguishing other biophysical vegetation characteristics such as level of biomass.

\section{Optical/IR Wetland Mapping Background}

Multispectral data that includes near infrared and shortwave infrared bands allow improved wetland detection and mapping over visible sensors alone. The near-infrared portion of the electromagnetic spectrum has been used to identify plant and hydrologic wetland conditions using both color infrared (CIR) aerial photography and satellite remote sensing systems (Ozesmi and Bauer, 2002). The most broadly used wetlands map in the United States, the National Wetlands Inventory (NWI), uses aerial CIR photography and photo interpretation techniques to provide fine scale maps of wetland distribution (Peters, 1994). However, this labor-intensive methodology requires a 10-year repeat interval for new map production (Wilen and Frayer, 1990).

To effectively monitor changes to wetlands, data collection must be timely (1-5 year minimum) and cost effective. The National Oceanic and Atmospheric Administration's Coastal Change and Analysis Program (C-CAP) uses the Landsat Thematic Mapper (TM) sensor to provide a more timely and cost effective national system of coastal wetland maps (Klemas et al., 1993) on a 5 year repeat interval. However, both NWI and NOAA C-CAP maps offer only broad classes of wetland, such as estuarine emergent or palustrine forested. Finer classes of actual species or ecosystem types are not mapped.

Since various targets reflect and absorb solar radiation differently, they can often be distinguished by their spectral reflectance signatures (Jensen, 2007). Spectral reflectance studies have been useful for determining regions of the electromagnetic spectrum which provide greatest discrimination between two or more wetland species (Schmidt \& Skidmore 2003, Becker et al 2005). However, many studies have concluded that it is difficult to accurately classify wetland species types based solely on Optical/IR spectral characteristics (Ozesmi and Bauer, 2002). 


\section{Satellite SAR Wetland Mapping}

SAR data have unique capabilities because the long microwave wavelengths penetrate vegetation cover and are sensitive to wet soil and flooded conditions that may exist beneath a canopy. An enhanced signature is often received from a canopy underlain by water due to a double-bounce effect of the incoming radiation from the smooth water surface and vertical stems of the canopy. The microwave scattering received by a SAR sensor from a wetland is dependent upon the wavelength, polarization, and incidence angle at which the energy was transmitted, the surface roughness, vegetative biomass, dielectric properties of the vegetation and soils (moisture in the plant canopy and on the ground), and the presence or absence of a flooded surface. Therefore, the SAR wavelength, polarization and incidence angle need to be carefully chosen to maximize the scattering to distinguish wetlands from uplands and to distinguish between wetland ecosystem types. A combination of wavelengths, polarizations, and/or incidence angles provides the most information about the various wetlands and thus the greatest capability to effectively map wetland ecosystem types with SAR.

Current and recently orbiting SAR satellites available commercially are of three different wavelengths; L-band ( $\sim 23 \mathrm{~cm}$ wavelength); C-band ( $\sim 5.7 \mathrm{~cm}$ wavelength), and X-band ( 3.5 $\mathrm{cm}$ wavelength). Of these SAR satellites, many are of a fixed incidence angle, but some have varying incidence angles. To detect flooding beneath a vegetation canopy, steep incidence angles (<35 degrees) are generally best (Hess et al. 1990). For temperate, sub-tropical and boreal regions, longer wavelengths such as L-band are more useful for mapping forested and high biomass herbaceous wetlands than C-band or X-band. C-band or X-band data have limited ability to map flooding beneath forest canopies. C-band data are most useful in forests during leaf-off condition and for sparse canopies, and have been used to map extent of inundation in floodplain swamps of Roanoke (Townsend 2001, 2002, Lang et al. 2008).

In Figure 1, theoretical scattering of a C-band sensor from forested versus herbaceous landscapes in various dry to flooded conditions is shown. Here it is demonstrated how the degree of inundation affects the scattering from the herbaceous canopy. In the case of wet soils and low inundation in an herbaceous canopy, enhanced backscatter is often observed at C-band, with some double-bounce effects. However, as the water levels increase the backscatter can first get stronger and then lessen until it reaches a low specular reflection case (where scattering is away from the sensor) from the water surface in the highly inundated situation (Kasischke and Bourgeau-Chavez 1997, Kasischke et al. 2003, BourgeauChavez et al. 2005). Figure 1 also shows the typical scattering from a closed versus open canopy forest at C-band. With most scattering from the branches and leaves at C-band in the closed canopy case, and little to no penetration to the ground surface. However, the longer wavelength L-band generally penetrates a closed canopy forest and has been found to be best for discriminating flooded from non-flooded forests (Hess et al. 1990, Ramsey 1998, Bourgeau-Chavez et al. 2001). C-band is best for discriminating emergent wetlands from agriculture and herbaceous uplands (Bourgeau-Chavez et al. 2001).

SAR polarization is also important, and horizontal send and receive $(\mathrm{HH})$ polarization has been found to be most useful for detecting wetlands. While, the cross-polarizations (Horizontal send and Vertical receive HV) are necessary for discrimination of woody versus 
herbaceous vegetation types due to their sensitivity to biomass (Ramsey 1998). VV polarization is also sensitive to soil moisture and flood condition (Bourgeau-Chavez et al. 2001).

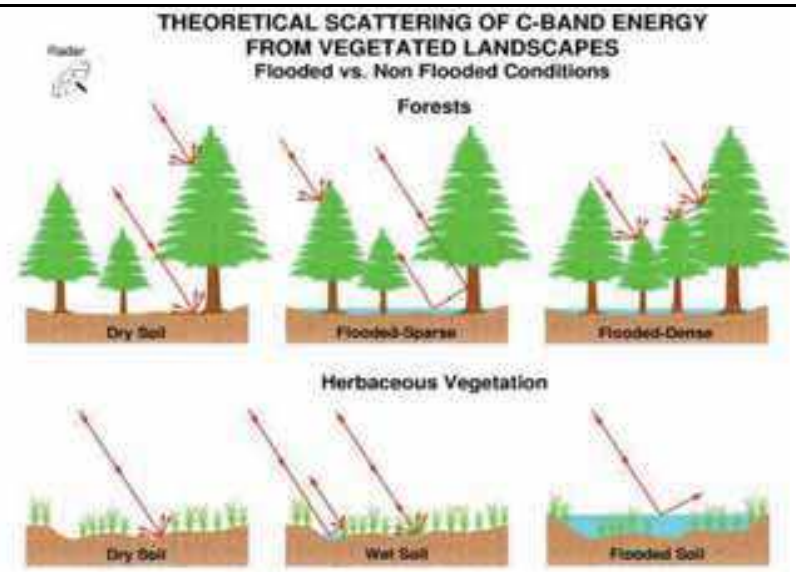

Fig. 1. Diagram showing theoretical scattering of C-band energy from forested and herbaceous ecosystems in dry, wet and flooded conditions, with open and closed forest canopies.

One primary advantage of using SAR over visible data is the detection of forested wetlands and the ability for SAR data to be collected irrespective of cloud cover or solar illumination because it is an active sensor. It is very difficult to detect flooding beneath a forested canopy with Optical/IR, unless there are large gaps in the canopy. Many researchers have found significant improvement in distinguishing swamp from other wetland classes and uplands with SAR (Lang et al. 2008, Grenier et al. 2007, Baghdadi et al. 2001, Hess et al. 1990, Bourgeau-Chavez et al. 2004).

Several researchers have evaluated the utility of SAR for wetland mapping using single and multi-date single channel SAR data (Costa et al. 1998, Whitcomb et al. 2009, Arzandeh and Wang 2002, Rao et al. 1999) and others have evaluated polarimetric SAR (Hess et al. 1990, 1995, Bourgeau-Chavez et al. 2001, Pope et al. 1994, 1997, Crawford et al. 1999, Wang and Davis 1997, Touzi et al. 2007). See Henderson and Lewis (2008) and Ramsey (1998) for a more thorough review of past research on wetland ecosystem analysis with SAR. Many early studies conducted to determine the utility of multi-polarization/multi-frequency data, focused on NASA's Shuttle Imaging Radar - C (SIR-C) which was fully polarimetric at Land C-bands (L-HH, L-HV, L-VH, L-VV, C-HH, C-HV, C-VH, C-VV and X-VV) and fully polarimetric AirSAR (P-band $(72 \mathrm{~cm}), \mathrm{L}-$ band, C-band) for wetland classification in tropical and temperate landscapes (Hess et al. 1995, Pope et al. 1994, 1997, Bourgeau-Chavez et al. 2001). These studies demonstrated the utility of multi-band data and early polarimetric analyses (e.g. HH-VV phase difference) for mapping forested and herbaceous wetlands (Pope et al. 1997). 
While several researchers have evaluated the use of SAR alone for mapping wetlands, until more recently, few have evaluated SAR and Optical/IR fusion for wetland mapping (Lozano-Garcia and Hoffer 1993, Augustein and Warrender, 1998, Toyra et al. 2001, Rio and Lozano-Garcia 2000, Bourgeau-Chavez et al. 2004, 2008, 2009, Li and Chen 2005, Grenier et al. 2007). Since the SAR and Optical/IR data measure different features of wetlands, it is logical that a synergistic approach between the two sensor types would increase wetland mapping accuracy. Further since the presence of standing water causes the SAR energy to interact differently depending on the dominant vegetation type, it would be advantageous to combine SAR with optical and infrared data for mapping purposes.

\section{SAR and Optical Data Fusion}

Of the few broad-scale SAR wetland mapping efforts that have been undertaken, , Canada is incorporating Radarsat- 1 and Radarsat- 2 data with Landsat mosaics (100m resolution) and SPOT data in the development of the Canadian Wetland Inventory (Grenier et al. 2007, Fournier et al. 2005, pers. comm. Grenier 2009) which will cover the entire country. There is also an effort underway to use the JERS mosaics (100 m resolution summer and winter products) of Boreal North America alone to map wetlands across Canada, as has already been done for Alaska (Whitcomb et al. 2009).

In this chapter, we review case study of multi-sensor, multi-date, SAR-optical/IR fusion methods and results for mapping wetlands in two main study areas, the Great Lakes and a Boreal peatland region in Alberta, Canada. The techniques are developed with broad scale mapping in mind, but are demonstrated on local to regional wetland areas. In all but one of these case studies, satellite SAR data are used in conjunction with Landsat TM, and in most cases SAR data from multiple sensors are fused. The exception, is the case studies on mapping the invasive plant species Phragmites australis on Lake St. Clair, where PALSAR data are used alone and compared to hyperspectral AVIRIS.

\subsection{Case Study: Lakes Ontario and St. Clair Coastal Wetland Mapping}

The Great Lakes Coastal Wetlands Consortium (GLCWC) was mandated to develop a monitoring plan for assessing the health of the coastal wetlands which are vital to the overall health and maintenance of the Great Lakes ecosystem (Bourgeau-Chavez et al. 2004, 8). The only way to monitor an ecosystem the scale of the Great Lakes basin is through integrated remote sensing and field observations in a GIS. Landscape indicators in need of monitoring through remote sensing include wetland type and extent, adjacent land cover, adjacent land use, intensity of land use, and invasive plant species. The GLCWC sought implementable, cost-effective yet robust methods with a minimum mapping unit of 5 acres. To meet these needs a few pilot studies were conducted to demonstrate various monitoring methods. A hybrid SAR Optical/IR methodology that used satellite sensor data of $30 \mathrm{~m}$ resolution and would allow for detection of areas as small as 1 hectare was found to be the most promising. This methodology would be cost-effective and data management for the entire Great Lakes Basin would be reasonable compared to higher resolution, smaller footprint imagery. And the use of two complementary data types in the mapping was expected to reduce omission and comission errors. 
Two study sites were selected for demonstration of this hybrid SAR-optical data fusion, coastal areas of Lakes St. Clair and Ontario (Figure 2). Coastal Lake St. Clair was chosen because it has a diversity of land cover and land use including a large amount of urban and suburban areas, rural farm fields, and a large amount of wetlands (various species) that occur at the delta as the river enters the lake. The Lake Ontario study area was chosen because it is mainly rural, with many agricultural fields, has isolated patches of herbaceous wetlands, and a relatively large amount of potentially forested wetlands. These two areas provide different sets of land cover and land use classes and thus an opportunity to test the hybrid-sensor methodology in diverse settings.

\subsubsection{Remote Sensing Data}

The data used in this case study were archival SAR and Landsat data from multiple dates, and multiple sensors (Table 1). For the Landsat images, each containing 7 bands, the blue and thermal IR bands for each date were removed from the analysis. The blue channel is generally quite noisy and the thermal band is of coarser resolution than $30 \mathrm{~m}$. The JERS (Lband) sensor used for this project had horizontal send and receive polarization (L-HH) and was operational from 1992-8. This sensor has a resolution of $30 \mathrm{~m}$, incidence angle of $35^{\circ}$, and a footprint of $80 \mathrm{~km} \times 80 \mathrm{~km}$. To complement these data, we also acquired C-band (5.7 $\mathrm{cm}$ wavelength) SAR data from the European ERS-1 and Canadian Radarsat-1 (R-1) satellites. The ERS-1 sensor has vertical send and receive polarization (C-VV) and is collected at a central incidence angle of $23^{\circ}$. The Radarsat sensor has horizontal send and receive polarizations $(\mathrm{C}-\mathrm{HH})$. It also has pointing capabilities and can be collected in various modes and incidence angles. The R-1 data used were of standard beam 7 mode, which has an incidence angle of $47^{\circ}$. Both C-band sensors have $30 \mathrm{~m}$ resolution and $100 \mathrm{~km} \times 100 \mathrm{~km}$ footprints.

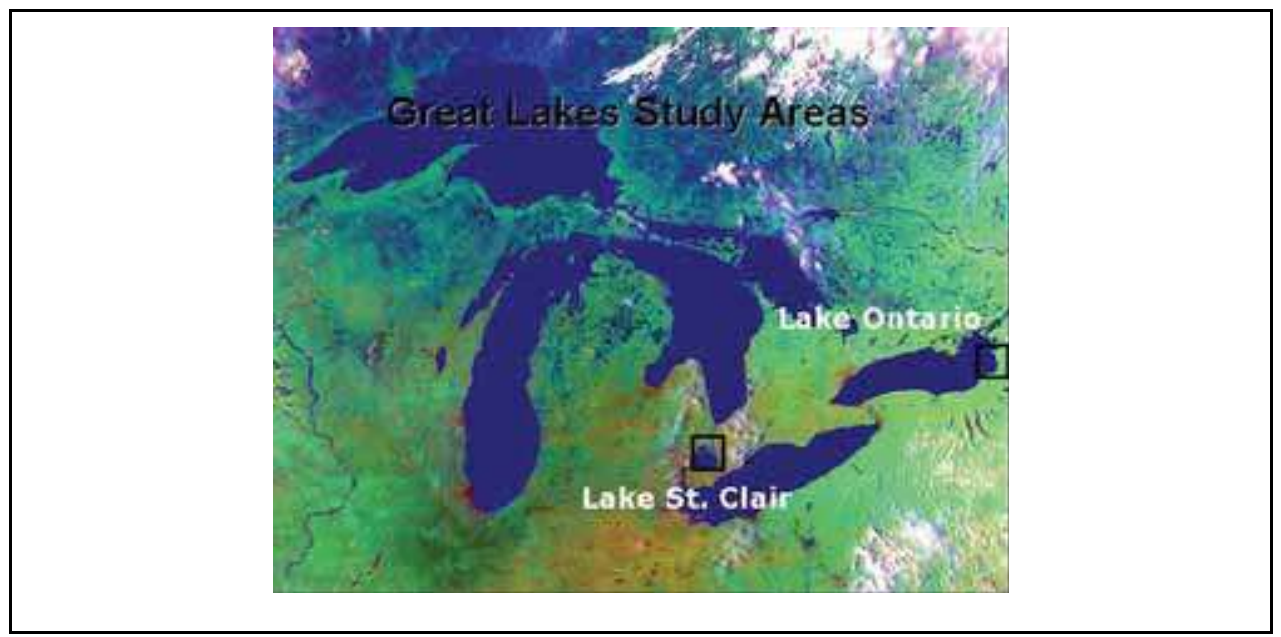

Fig. 2. Great Lakes pilot study areas for hybrid SAR-Optical/IR mapping for the Great Lakes Coastal Wetlands Consortium project. 


\begin{tabular}{|l|l|l|l|l|}
\hline \multicolumn{1}{|c|}{ Site } & \multicolumn{1}{|c|}{ Sensor } & \multicolumn{1}{c|}{ Spring } & \multicolumn{1}{c|}{ Summer } & \multicolumn{1}{c|}{ Fall } \\
\hline Lake St. Clair & $\begin{array}{l}\text { Landsat } \\
\text { TM }\end{array}$ & 23 March 2001 & $\begin{array}{l}\text { 30 August } \\
2001\end{array}$ & 30 October 2000 \\
\hline Lake St. Clair & JERS & 28 March 1995 & $\begin{array}{l}10 \text { August } \\
1998\end{array}$ & \\
\hline Lake St. Clair & Radarsat-1 & & & 3 \& 27 October 1998 \\
\hline Lake Ontario & Landsat & 24 June 1993 & $\begin{array}{l}\text { 12 August } \\
\text { 2002 }\end{array}$ & 18 December 2002 \\
\hline Lake Ontario & JERS & 11 April 1993 & 8 July 1993 & 17 October 1993 \\
\hline Lake Ontario & ERS-1 & 17 April 1993 & 7 June 1993 & 25 October 1993 \\
\hline
\end{tabular}

Table 1. Data used in the Great Lakes Hybrid SAR-Optical/IR wetland and landscape indicator mapping.

Since this was a demonstration project with minimal funding, data sets chosen were not optimal but were chosen based on cost and ease of availability (Table 1). At both sites three dates of Landsat data were used. There were a total of four radar scenes for Lake St. Clair and 6 radar scenes for Lake Ontario. There are as many as 6 years between the JERS and Landsat collections for Lake St. Clair and 10 years between data collections for Lake Ontario, but analysis of the imagery indicated that few major changes in land use have occurred in these areas during that time period. Also, it was not as much of an issue due to the methodology; a site would first be checked for vegetation cover in the more recent Landsat and then checked for flooding in the older SAR. However, it is realized that using data with such a wide time span will introduce errors. The optimal data set would be from the same year, with SAR and TM from the same months. However, the datasets met the needs of this investigation, which was simply to demonstrate a methodology.

\subsubsection{Image Interpretation}

For the Lake St. Clair site, the imagery and products were evaluated by comparison to the NWI, land cover/land use maps, field checks (October 2003) and expert field knowledge (Field ecologist/botanist Dennis Albert of Michigan Natural Features Inventory).

Although the ancillary maps and field work showed many forested wetlands within our study area, the dates of JERS imagery show all of the forests the same, very bright in the spring (March 1995) and all are gray in the summer scene (August 1998). It is likely that all of the forests have a wet ground cover in the spring scene, there may even be wet, melting snow on the forest floor causing the enhanced signature from all of the forests, and in August all of the forests are dry with full foliage. However, the differences in backscatter in the herbaceous vegetation are apparent on these two dates, as well as in the October Radarsat scenes.

Figure 3 shows a red-green-blue false color composite of the 3 October 1998 R- 1 scene, 10 August 1998 JERS scene, and 28 March 1995 JERS scene, respectively. In this composite, the orange areas were dominated by cattail (Typha spp.), and the green by Phragmites (Phragmites australis). Phragmites tends to be taller/denser and occurs in less wet locations than cattail. The red areas of the image are shorter and sparser vegetation, thus they do not cause enhanced backscatter at L-band, only at C-band. The red areas along the fingers of the delta are cattail and bulrush (Scirpus spp.) beds and the red area within Dickinson Island is a 
flood channel with wild rice (Zizania aquatica), open submergent and emergent vegetation (Dennis Albert). The dark area in the center of Dickinson island to the west of the kidney shaped light blue forest area is a wet meadow and appears to be dry in our October 1998 Cband scene, it has strongest backscatter in the L-band spring scene (blue channel), but not enhanced backscatter. This combination of R-1 and JERS allows for a good interpretation of this scene, discerning tall dense herbaceous vegetation from short sparse herbaceous vegetation, and different hydrological and biophysical properties.

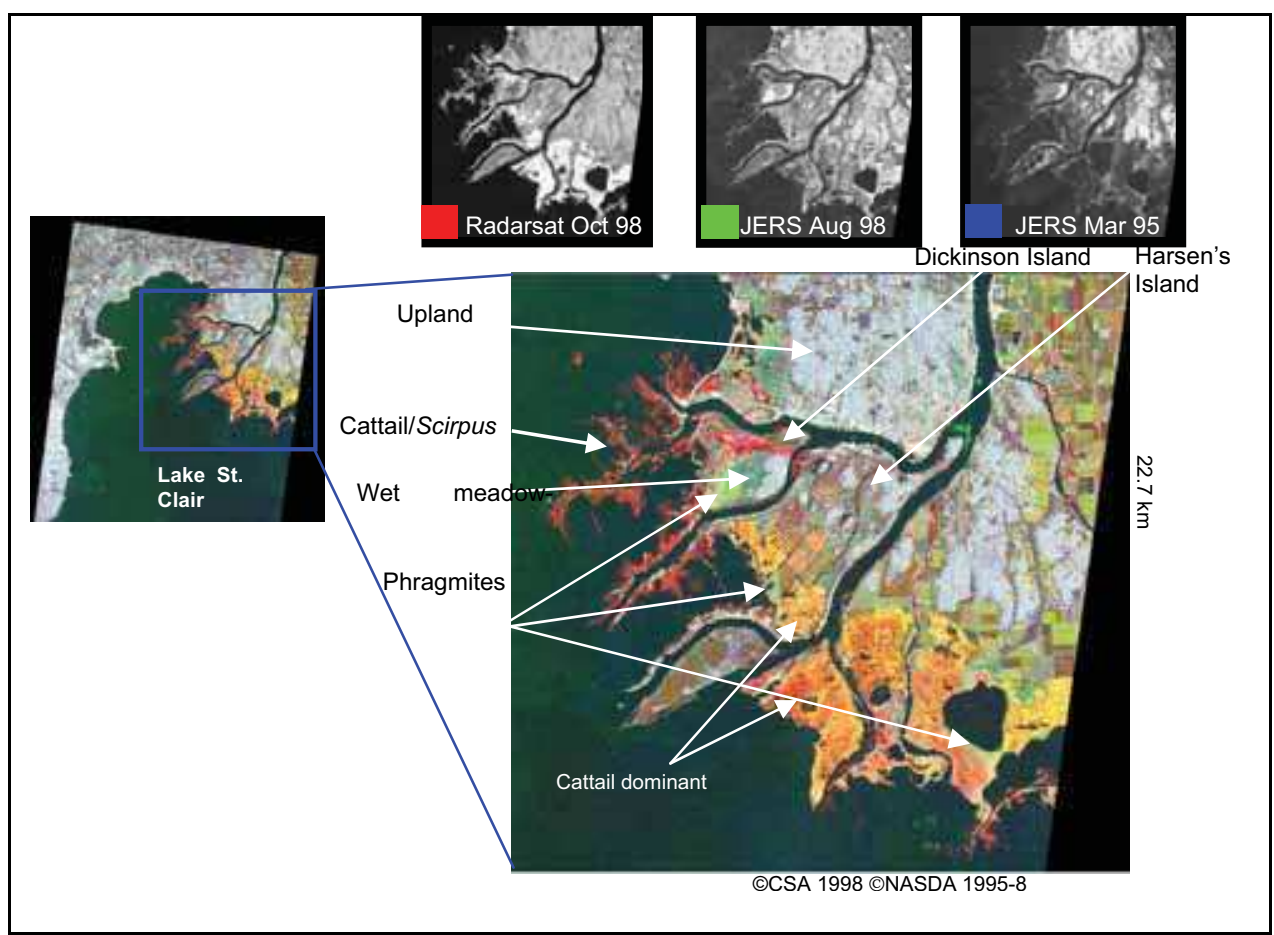

Fig. 3. Three dates, two sensor false color composites from Radarsat-1 and JERS satellites over the Lake St. Clair Delta. This Figure clearly defines Typha (cattail), and the invasive species Phragmites australis from other upland and wetland ecosystems.

At the Lake Ontario test site, we had an ideal seasonal data set with three images each of JERS and ERS from spring, summer and fall of 1993. Figure 4 presents false color composites of the two sensor datasets. Both datasets highlight non-forested wetlands (based on NWI) as green and red shades. In the JERS data, these sites were dark from specular reflection in the April scene (blue), then some sites were bright in July (green in the composite) while other sites remained dark in July (red locations in the composite) and all sites were gray in October (Table 2). In November of 2003, we conducted a field check to determine any vegetation difference between the red and green areas. The red areas visited were dominated by mixed grasses. It is likely that in the spring imagery the vegetation is fallen over or decomposed, with a high water level leading to specular reflection. The water level must still be high enough to cover much of the grasses and cause specular reflection again in 
the July scene, but when the lake water level drops to $74.58 \mathrm{~m}$ in October $(70 \mathrm{~cm}$ drop), this site has more vegetation exposed and stronger backscatter. In comparison, the green areas visited in the field contained a mixture of grasses, cattail and shrubs (mainly Cornus stolonifera). These sites were bright in the summer and gray in the fall in the JERS imagery. The water level in comparison to the vegetation was likely lower than at the other sites, causing the enhanced backscatter in July, but with lower soil moisture in the fall the site was gray. For the same two sites in the ERS, the grass site was dark in the spring but the mixed shrub/herbaceous site was gray. In the summer the mixed shrub site was bright while the grass site remained dark. In the fall all sites were gray. While similar patterns emerged for both sites, the contrast between the non-flooded adjacent forests and the wetlands is stronger with the JERS, making it easier to map the boundaries of the sites.

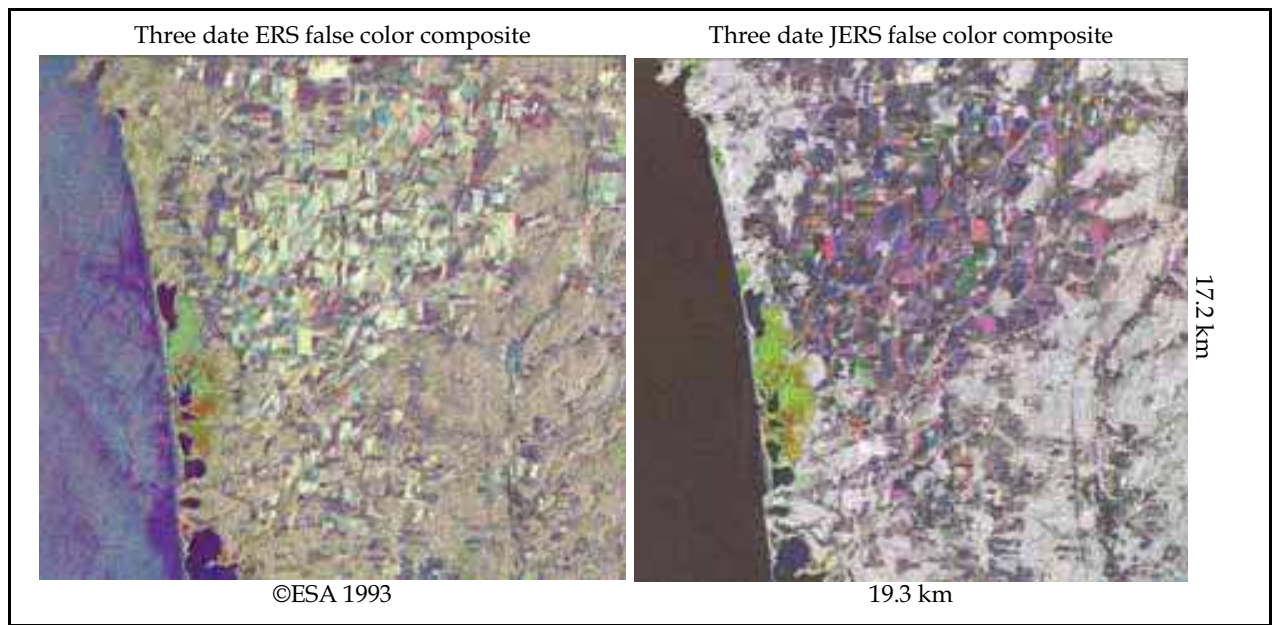

Fig. 4. Three date ERS false color composite of 25 October, 7 June and 17 April 1993 ERS imagery over eastern Lake Ontario compared to a 17 October, 8 July and 11 April 1993 JERS composite.

\begin{tabular}{|l|l|l|l|l|}
\hline \multicolumn{1}{|c|}{ Site } & \multicolumn{1}{c|}{ Sensor } & \multicolumn{1}{c|}{$\begin{array}{c}\text { Spring } \\
\text { Brightness }\end{array}$} & \multicolumn{1}{c|}{$\begin{array}{c}\text { Summer } \\
\text { Brightness }\end{array}$} & Fall Brightness \\
\hline Grass & ERS-1 C-VV & dark & dark & gray \\
\hline Shrub/herbaceous & ERS-1 C-VV & gray & bright & gray \\
\hline Grass & JERS L-HH & dark & dark & gray \\
\hline Shrub/herbaceous & JERS L-HH & dark & bright & gray \\
\hline
\end{tabular}

Table 2. Appearance of "grass" versus "shrub/herbaceous" sites in coastal Lake Ontario in spring, summer and fall of 1993. Grasses are red areas in JERS composite of Figure 3 and Shrub/herbaceous are green areas.

There are some forested wetlands within the Lake Ontario scene and they appear to be most notable in the April scene when the lake water level is the highest (note that coastal wetlands are hydrologically connected to the Great Lakes), and spring thaw has occurred and thus flooding is most likely. A comparison was made between assumed flooded forest and non-flooded forest for each JERS scene/date. The April scene had a $2.3 \mathrm{~dB}$ difference 
between flooded and non-flooded forest while the July date had only a $0.5 \mathrm{~dB}$ difference and the October date had a $1.7 \mathrm{~dB}$ difference. The April scene was then thresholded to values greater than that of the non-flooded forest. After median filtering the scene with a $5 \times 5$ window to remove speckle, the scene was overlaid on a 5, 4, 3 Landsat composite (Figure 5). The white areas of Figure 5 show the SAR-derived potentially flooded forests. The backscatter from urban areas is also enhanced and has not been filtered from this scene. There are also white areas that are likely row plantings of trees. The row structure produces an enhanced return. The urban areas can be removed by using either the Landsat scene to mask forest from non-forest or by using the ERS C-band data. The C-band data will have enhanced backscatter for the urban area but not for the flooded forests. The extent of some of the enhanced signatures appears to be slightly greater than what is seen in the NWI for some of the sites (Figure 5) and in other cases it is less.

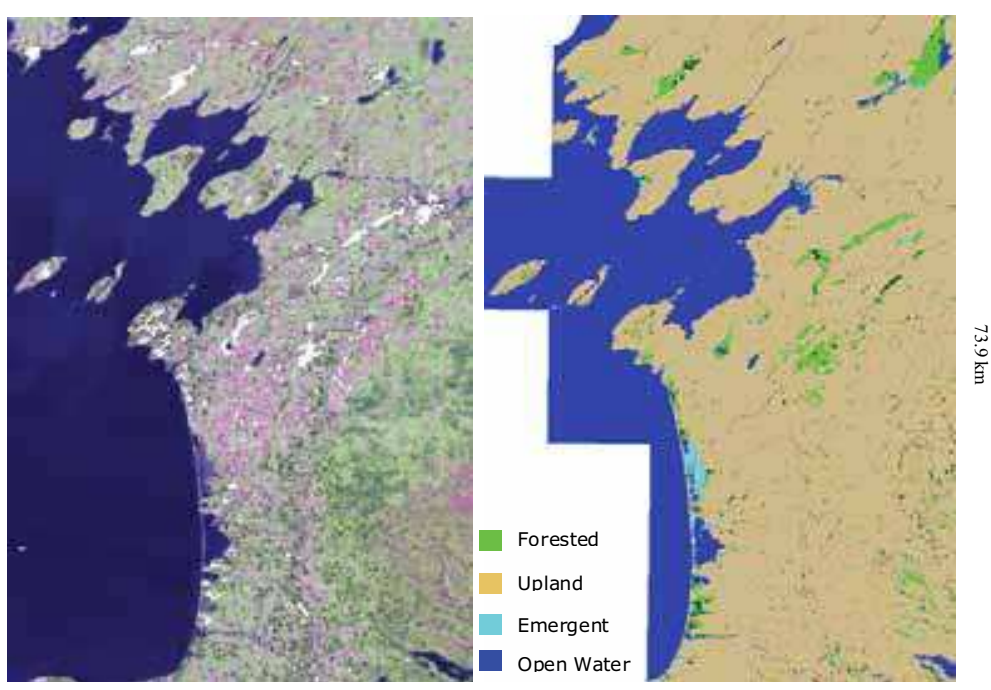

Fig. 5. Landsat 5, 4, 3 composite with SAR-derived potentially flooded forests (white areas) overlaid 9 (left). The NWI is presented for comparison (right) with forested wetlands colored green. Note that the NWI is not the exact area of the Landsat scene.

One technique that has been used somewhat operationally for detecting forested wetlands, is to map forest cover with Optical/IR and then create either a single-date thresholded image, as is presented here, or a multi-date SAR image to determine inundation and thus, forested wetland. Using remote sensing to detect flooding beneath a canopy is limited by the timing of the data acquisitions. Therefore, only the forests that were inundated on the date of image acquisition will be mapped as forested wetland. The multi-season data helps reduce this limitation, but relying on species type and other ancillary data such as hydric soils, as well as enhanced SAR backscatter to determine wetland status would be more reliable, hence hybrid approaches are recommended. One useful parameter the SAR can be used for is to monitor changes in extent of inundation from one date to the next (BourgeauChavez et al. 2005, Lang et al. 2008, Townsend 2001, Wang et al. 2004). 


\subsubsection{Mapping Methodology}

Several techniques were considered and evaluated for merging the multi-sensor, multi-date Great Lakes datasets and producing a land cover land use map, but the best method appeared to be the simplest, which involved creating separate SAR and Landsat land cover/land use products and then fusing the products in a GIS. This method preserved the unique characteristics of each sensor, while taking advantage of their complementary nature.

\subsubsection{Lake St. Clair Study Site}

The two-step methodology was first applied to the Lake St. Clair study site where the 15band Landsat layer was classified into 12 different land cover features using the maximum likelihood classification algorithm. The training sites for this supervised classification were collected from the reference field data and existing maps. The 12 classes created were: Water, High Density Urban, Low Density Urban, Forest, Emergent Wetland, Wetland Shrub, Wetland-permanent, Forage Crops, Cropland 1, Cropland 2, Cropland 3, Cropland 4. The second step of the process involved the classification of the 4-band radar image into 9 different classes. These classes were different than that of the Landsat imagery because the sensors are able to distinguish different phenomena. The classes for the radar classification were: Forest/Urban, Phragmites, Scirpus/ open submergent and emergent, Cattails, Wet Meadow, Forage Crops, Cropland1, Cropland2, and Cropland3

The individual classification results were then fused into a single classification. This was performed by recoding the 12-class Landsat classification into values of 10 s $(10,20,30 \ldots 120)$ and recoding the radar classification into values 1-9. Then the values were added together on a pixel-by-pixel basis, producing possible values between 11-129. These recombined classes were then interpreted, by comparison to the reference data, and assigned into a final 11-class file. This final class identification relied on only the Landsat for some classes (such as water, forest, low density urban), only the radar for others (Phragmites and Scirpus), and a combination of both for the majority of the classes. The final classes are described below in Table 3 and the final map is in Figure 6.

Due to limited funding and the archival nature of the dataset, an accuracy assessment was conducted based on existing maps. The NWI, which is the basemap for the GLCWC, was first used as a reference. Then IFMAP (Integrated Forest Monitoring, Assessment and Prescription), which relies on NWI to some extent, was used because it includes upland classes that NWI does not. IFMAP was produced by the Michigan Department of Natural Resources. It is mainly based on the analysis of seasonal Landsat imagery (collected between 1997-2001), but is supplemented with selected high resolution images, existing land cover maps, and large amounts of field work. IFMAP provides a very detailed description of land cover, but is only available for the Michigan portion of the study area and accuracy could therefore only be assessed on the U.S. side of the map. NWI and IFMAP have only broad wetland categories (e.g. palustrine emergent, scrub-shrub, etc). 


\begin{tabular}{|l|l|}
\hline \multicolumn{1}{|c|}{ Class } & \multicolumn{1}{c|}{ Description } \\
\hline Water & Identified through the Landsat, regardless of the radar results \\
\hline High Density Urban & $\begin{array}{l}\text { Identified by an urban class in the Landsat imagery and a } \\
\text { urban_forest (bright) from the radar class }\end{array}$ \\
\hline Low Density Urban & Identified through the Landsat, regardless of the radar results \\
\hline Scirpus & $\begin{array}{l}\text { Identified through the radar classification and reinforced by } \\
\text { being classified as a wetland/vegetative class in the Landsat } \\
\text { imagery }\end{array}$ \\
\hline Phragmites & $\begin{array}{l}\text { Identified through the radar classification and reinforced by } \\
\text { being classified as a wetland/vegetative class in the Landsat } \\
\text { imagery }\end{array}$ \\
\hline Cattail & $\begin{array}{l}\text { Identified through the radar classification and reinforced by } \\
\text { being classified as a wetland/vegetative class in the Landsat } \\
\text { imagery }\end{array}$ \\
\hline Wetlands_other & $\begin{array}{l}\text { Identified as wetlands in the landsat imagery but is different } \\
\text { than Scirpus, Phragmites, and cattail }\end{array}$ \\
\hline Shrubland (shrub wetland) & $\begin{array}{l}\text { Identified through a Landsat class of shrubland and forest and } \\
\text { has a radar classification of wet meadow or shrubland }\end{array}$ \\
\hline Cropland & $\begin{array}{l}\text { Identified by the four cropland classes from the Landsat imagery } \\
\text { and the three cropland classes from the radar classification. }\end{array}$ \\
\hline Forage Crops/Low Herbaceous & $\begin{array}{l}\text { Identified by landsat imagery (forage, row crop) and radar } \\
\text { imagery (forage) }\end{array}$ \\
\hline Forest & $\begin{array}{l}\text { Identified through a Landsat imagery forest class (Note: if the } \\
\text { radar were from a time when forested wetlands could be } \\
\text { identified, this landsat class would be combined with a radar } \\
\text { class) }\end{array}$ \\
\hline
\end{tabular}

Table 3. Combined Landsat and radar landcover results for the Lake St. Clair study site.

Using over 3000 randomly selected validation points, comparison to the NWI as reference, resulted in $94 \%$ overall accuracy of our wetlands map. Comparison to IFMAP resulted in $72 \%$ overall accuracy when areas of wetland that IFMAP called "open water"were eliminated. Analysis of the imagery revealed that the timing of data collections and the lake levels can have a large effect on the boundaries mapped for emergents along the water's edge. A SAR comparison of 2 image dates with a change of $19 \mathrm{~cm}$ in lake level showed a huge change in visibility of wetlands on the fingers of the St. Clair river delta (Figure 7). In this figure, lake water level is $19 \mathrm{~cm}$ higher on the first date, causing specular reflection (low return-dark). A decrease in inundation on the second date reveals the vegetation causing double bounce scattering (bright return-red). This exemplifies the need for multi-date data to "see" the wetlands that may be nearly completely inundated by water on a particular date in both SAR and optical/IR.

In comparison to IFMAP, the hybrid SAR-Optical classification did well with low density urban, Typha, Phragmites, low herbaceous, Scirpus and cropland (all above 60\% user's accuracy, Typha above $86 \%$ ). There were some issues with wet meadow (42.25\% user's accuracy) where there is confusion in IFMAP with tree species, row crop and herbaceous upland. Further investigation of this type is needed. The classes were quite different for IFMAP, but for lowland deciduous, the SAR-Optical map had $81 \%$ producer's accuracy, $65 \%$ and $77 \%$ producer's accuracy for emergent and non-forested wetland and $78 \%$ producer's accuracy for low density urban. 
A visual comparison was also made between our classification of the Canadian side of the study area using maps produced by Arzandeh and Wang (2002 \& 2003) of Walpole Island, Ontario. In 2002 Arzandeh and Wang used a single Radarsat scene (1997) and Landsat data (1997), separately, to create two classification maps with eight categories including forest, urban, swamp, tall grass, water, agriculture, cattail and Phragmites. Their areas of emergent wetland (cattail and Phragmites) correspond well with the areas that we have mapped as emergent. However, their maps lack the detail that we gained by combining multiple dates and two bands of SAR imagery with the Landsat. Their goal was to use texture analysis of a single date of SAR imagery to improve classification accuracy with a single date of SAR. Generally, more than one date of imagery is available, but for those cases when only one date of imagery exists or can be acquired their techniques would be useful.

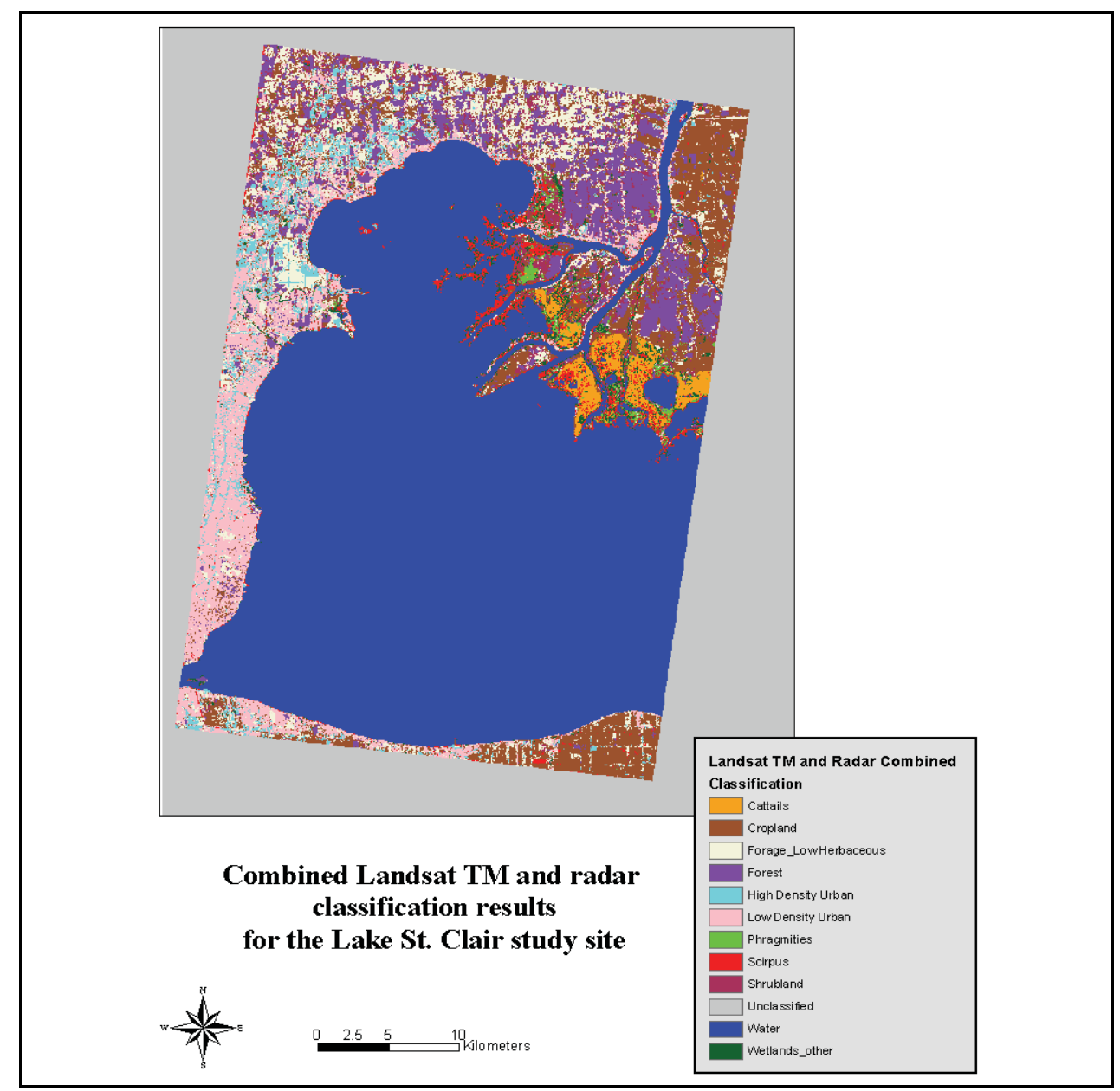

Figure 6. Landsat and SAR fused land cover classification results for the Lake St. Clair study area. 


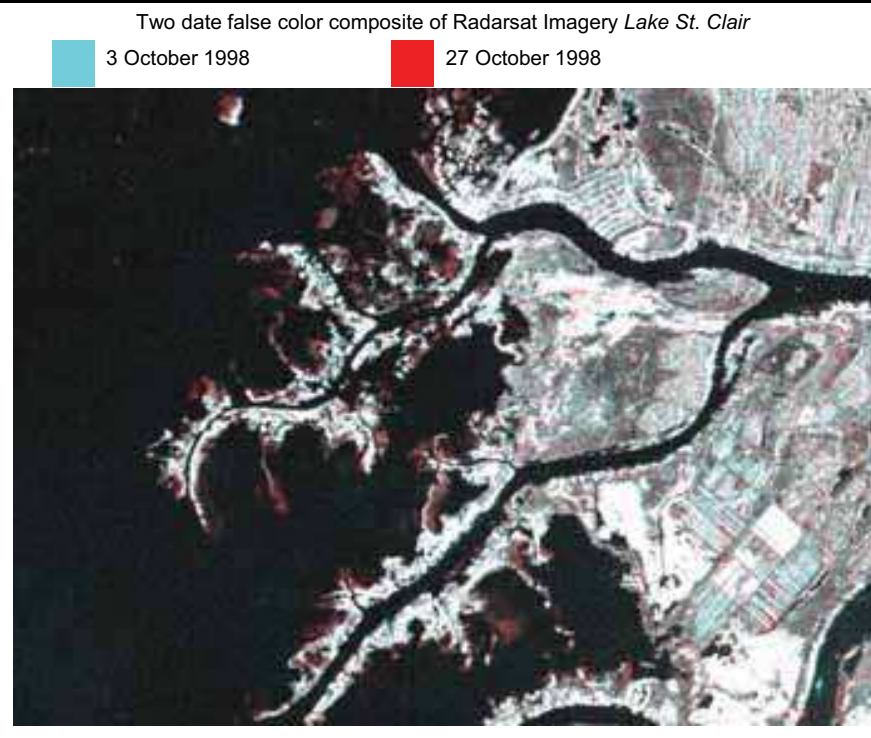

Fig. 7. Two date false color composite of Radarsat imagery. Cyan is the 3 October 1998 image and red is the 27 October 1998 image. Water level dropped by $19 \mathrm{~cm}$ between the first and second date.

\subsubsection{Lake Ontario Study Site}

The same techniques used for Lake St. Clair were applied to the datasets for Lake Ontario, however the classes were slightly different. First, Landsat imagery was classified into 13 different landcover classes; Water, High Density Urban, Low Density Urban, Deciduous Forest,Coniferous Forest, Mixed Forest, Row Crops, Low Herbaceous, Bare Soil, Emergent Wetlands, Shrubland, Fields-Hay, Wetlands-other. The radar imagery was classified into 9 classes; Water, Urban/Flooded Forest, Flooded Shrubland/ Wet Meadow, Emergent Wetland, Forest1, Forest2, Row Crop 1, Row Crop 2, and Herbaceous Field. These individual Landsat and SAR classes were then fused into a single product, just as they were for Lake St. Clair. The 12 final combined classes are described in Table 4. The final map is presented in Figure 8.

A comparison was made between the SAR-Optical map and the NWI with 5000 random points Note that the NWI has more generalized classes so the comparison is not straight forward, and there are over 2 decades between the NWI creation and the SAR-Optical/IR map, so some differences may be due to changes in the wetland, either succession or loss. The results in comparison to the NWI showed $94 \%$ overall accuracy, with all classes greater than $89 \%$ user's accuracy, except shrubby wetland for which we only had 13 points, none of which were correctly classed. The producer's accuracy in the wetlands was $34 \%$ for woody wetland and $66 \%$ for emergent. For the NWI woody wetlands, we labeled 127 out of 208 as deciduous forest. The problem likely lies in what areas were in fact inundated during the radar satellite collections. A wet, normal or dry year will provide different wetland extents, $66 \%$ agreement for emergent wetlands is quite good considering the likely turnover of some 
areas to agriculture and the likely succession of some of the wetlands labeled as emergent in the 1970s NWI to wetland shrub, as indicated by the field visits and point source field data from a biocomplexity study conducted by Cornell University (Mark Bain).

\begin{tabular}{|l|l|}
\hline \multicolumn{1}{|c|}{ Class } & \multicolumn{1}{c|}{ Description } \\
\hline Water & Areas identified as water in the Landsat imagery, regardless of the radar classification \\
\hline High Density & $\begin{array}{l}\text { Areas dominated by manmade materials, these areas were identified by high radar } \\
\text { returns that were not forested areas in Landsat }\end{array}$ \\
\hline Low Density Urban & $\begin{array}{l}\text { Areas with a mixture of manmade features and landscape vegetation, these areas were } \\
\text { mainly identified by the Landsat classification }\end{array}$ \\
\hline Deciduous Forest & $\begin{array}{l}\text { Areas of forest that lose their leaves throughout the season, identified through a } \\
\text { combination of the Landsat and radar classifications }\end{array}$ \\
\hline Coniferous Forest & Areas of evergreen forest, identified through the combination of classifications \\
\hline Mixed Forest & $\begin{array}{l}\text { Areas that are a mixture of coniferous forest and deciduous forest, identified through a } \\
\text { combination of classifications }\end{array}$ \\
\hline Forested Wetland & $\begin{array}{l}\text { Areas are forest but have standing water on the ground throughout much of the year, } \\
\text { identified as forest in the Landsat imagery and as urban/flooded forest in the radar } \\
\text { imagery }\end{array}$ \\
\hline Emergent Wetland & $\begin{array}{l}\text { Areas of herbaceous vegetation that are wet at some times of the year, identified } \\
\text { through the combination of radar classification and Landsat classification }\end{array}$ \\
\hline Wetland-shrub & $\begin{array}{l}\text { Areas of short woody vegetation that are wet at some points throughout the year, these } \\
\text { are identified through the combination of sensor classification results. }\end{array}$ \\
\hline Crop/pasture & $\begin{array}{l}\text { Areas of herbaceous vegetation that are not plowed throughout the year, mainly } \\
\text { identified through the Landsat classification }\end{array}$ \\
\hline Bare Soil & $\begin{array}{l}\text { Areas of exposed soil, sand, and/or rock, these areas were mainly identified through } \\
\text { the radar and were confirmed by the Landsat classification }\end{array}$ \\
\hline Row Crop & $\begin{array}{l}\text { Areas that have herbaceous vegetation growing which is plowed at some point during } \\
\text { the season. These areas were identified through a combination of the classification } \\
\text { results. }\end{array}$ \\
\hline
\end{tabular}

Table 4. Classes for the combined Landsat and radar classification at the Lake Ontario study site.

The state of New York did not have a land cover/land use map comparable to IFMAP, and many errors were found in the National Land Cover Dataset (NLCD). However, field data collected in the largest coastal wetland complex in the image were available with GPS locations. The Biocomplexity study of Cornell University allowed for comparison of the SAR-Optical/IR hybrid map to 55 study points which represented cattail dominated, shrub, forested, and mixed emergent wetlands. The overall accuracy of this comparison was $89 \%$, with $91 \%$ user's accuracy for wetland shrub, $89 \%$ user's for emergent wetland, and $67 \%$ for forested wetland. This assessment is quite good considering the likelihood of error in the geolocation of the study points due to the small plot size in reference to the $30 \mathrm{~m}$ pixels. Some of the points did fall on boundaries of open water/wetland or upland/wetland causing errors. The producer's accuracy ranged from 25 to $75 \%$ in the reference categories of specific species types that we did not map. The cattail field points corresponded to the wetland shrub (dark pink) areas in the Landsat-SAR fused classification. Therefore, the pink areas of our Landsat-SAR map should be labelled as shrub/high biomass herbaceous wetlands. 


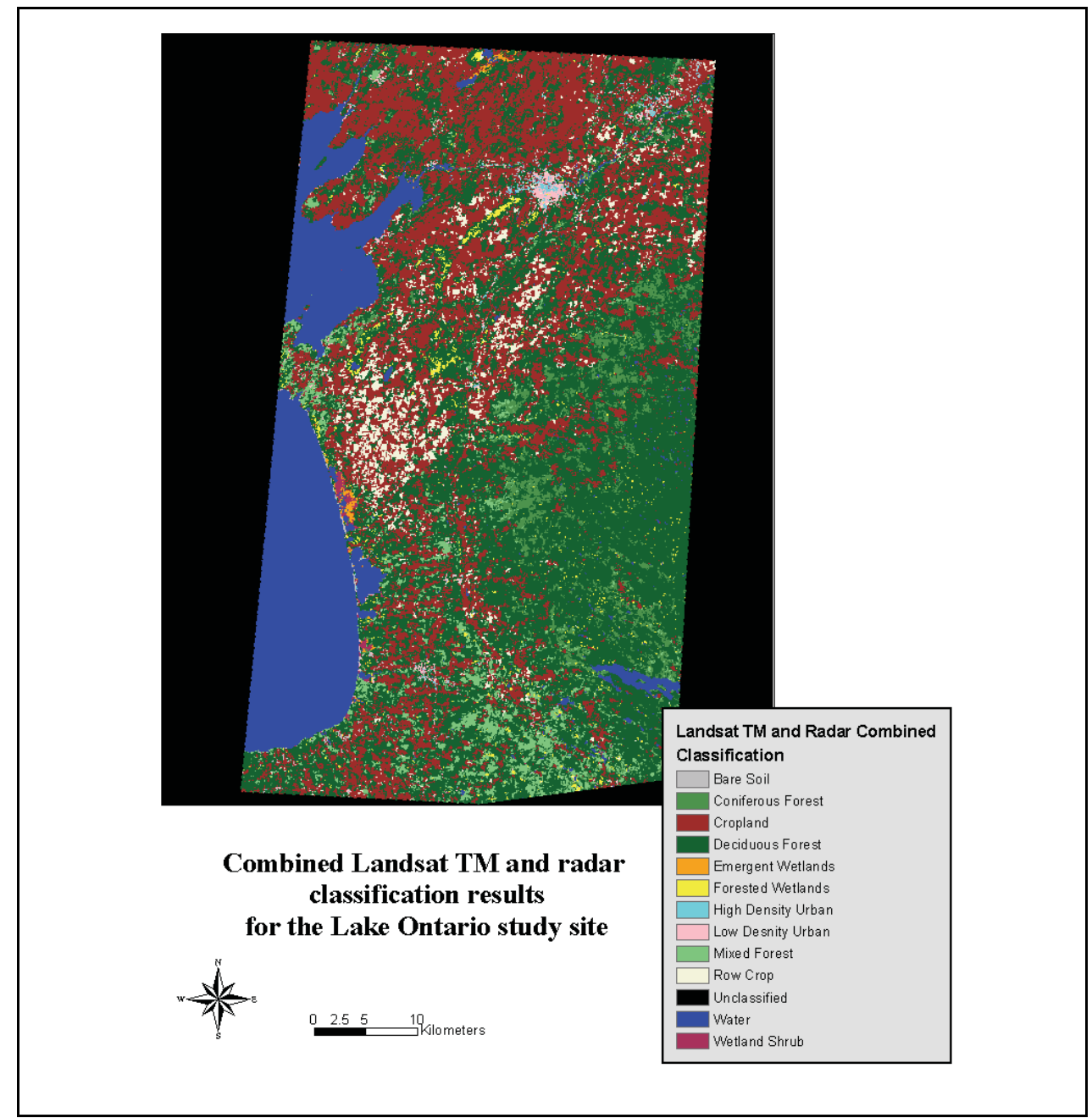

Fig. 8. Landsat and SAR fused land cover classification of the Lake Ontario study area.

\subsubsection{Summary}

These two study areas demonstrated the utility of a fusion of SAR and Optical/IR data for mapping landscape indicators of wetland health (wetland extent, adjacent land use intensity, etc.) in a region surrounded by high intensity urban versus a more rural area. In one case mapping of forested wetlands was possible and in the other, timing of data collections did not allow evaluation of forested wetland mapping. However, a simple approach to the mapping provided desirable results with the archival data, showing the complementary nature of the two types of sensors. Although the reference data and remote sensing data were not optimal [there are discrepancies in years of data collection (Landsat versus SAR (1990s-2001) and years of validation maps (1970s, 2000) and levels of vegetation 
classes between the SAR-Optical map and validation maps (fine scale species versus broad emergent classes)], these case studies demonstrated the added benefits of fusing Optical/IR data with another complementary sensor such as radar and resulted in a recommendation by the Great Lakes Coastal Wetlands Consortium for monitoring landscape indicators (Bourgeau-Chavez et al. 2008). In the next case study, current data are used and ongoing validation is being conducted for the specific species class levels. This case study is a continuing investigation and only preliminary results are shown here, however it provides a better validation of the results through field methods, further exemplifying the utility of SAR in wetland mapping.

\subsection{Case Study: Invasive Phragmites australis Species Mapping on Lake St. Clair}

One of the main wetland stressors in the Great Lakes is invasion by the problematic species Phragmites (Phragmites australis). This species invades native habitat creating dense thickets and deep detritus that virtually eliminates ecological function. A predicted drop in Great Lakes water levels due to global climate change is anticipated to increase the spread of the invasive Phragmites in the Great Lakes coastal zone, and a method to map this species and its spread would be of great assistance to land managers for control.

Several studies have focused on detecting and mapping invasive species in small catchments of the Great Lakes with high resolution hyperspectral and/or lidar (e.g. Lopez et al. 2006, Wilcox et al. 2003). However, such high-resolution mapping of the entire Great Lakes coastline or comprehensive field studies would be very costly. Others have found 30 $\mathrm{m}$ satellite imagery including Landsat, SPOT and Hyperion to be useful for mapping invasives (Arzandeh and Wang 2003, Pengra et al. 2007), however Landsat has spectral limitations and Hyperion is no longer operational.

Using a variation of the satellite SAR techniques described in the last section, which included a delineation of this invasive species using archival multi-date JERS and RadarsatI, we are currently evaluating dual polarization PALSAR data, and have plans to incorporate Radarsat-2 data once it becomes available to distinguish a wider range of species.

\subsubsection{Remote Sensing Data}

ALOS PALSAR is the follow-on to JERS which showed the greatest potential in previous studies for mapping Phragmites (Bourgeau-Chavez et al. 2004, 2008). PALSAR was launched in 2006, and is available in three modes with various imaging parameters. Here we evaluate the dual-polarization product which has $20 \mathrm{~m}$ resolution, two channels (L-HH, L-HV), $70 \mathrm{x}$ $70 \mathrm{~km}$ footprint, and is collected at an incidence angle of $34^{\circ}$. Up until recently, most satellite SAR systems were of a single channel, however with the recent launch of ALOS PALSAR and Radarsat-2, the utility of multi-channel SAR and polarimetric data are beginning to be more broadly evaluated for a variety of applications, demonstrating further mapping capabilities beyond that of single and multi-channel data. 
Coincident to this evaluation is an investigation of an airborne hyperspectral NASA AVIRIS collection from July 2008 over the St. Clair delta. The AVIRIS sensor has 224 bands (400-2500 $\mathrm{nm})$ and was collected with $17 \mathrm{~m}$ resolution.

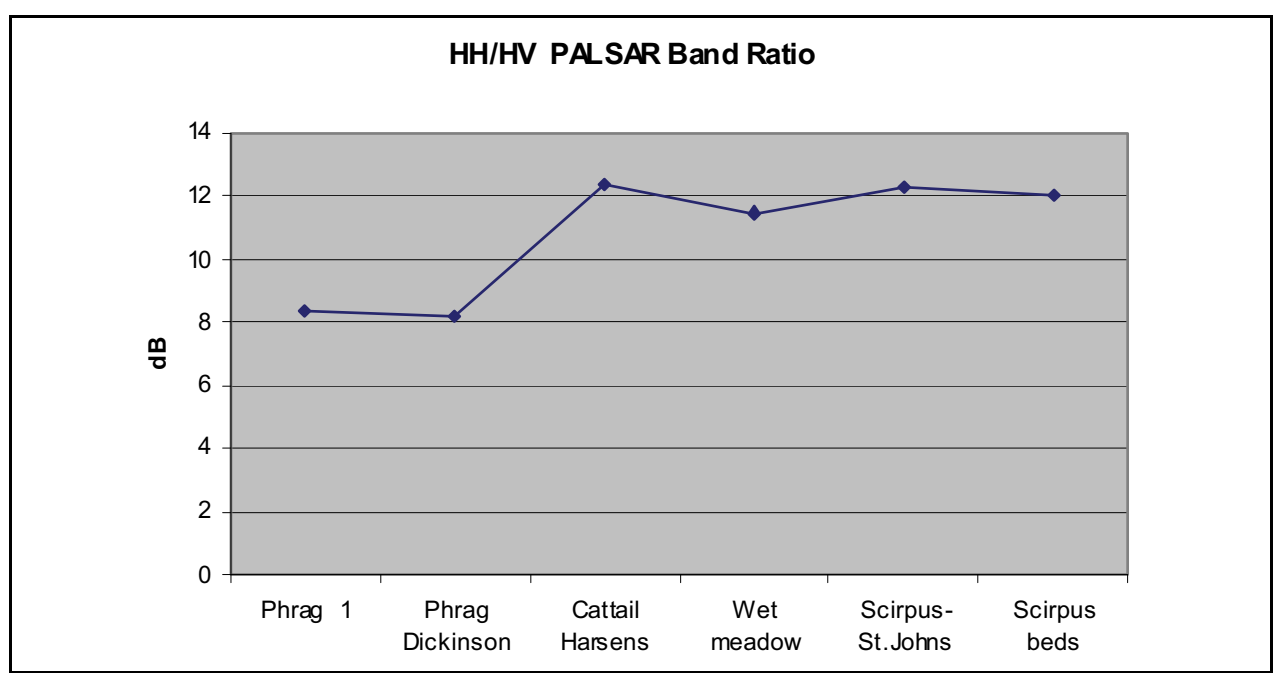

Fig. 9. Plot of backscatter from PALSAR (L-HH to L-HV ratio in dB) in Phragmites, Cattail, wet meadow and Scirpus beds of the Lake St. Clair delta.

\subsubsection{Image Interpretation}

Initial observations of an October 2007 dual polarization PALSAR image over Lake St. Clair revealed that the ratio of the L-HV and L-HH bands shows a $4-5 \mathrm{~dB}$ difference between Phragmites dominated wetlands and other non-forested native wetland types (Figure 9). The reason for this great divergence is the large difference in vegetation height, density and biomass of invasive Phragmites versus any other native herbaceous vegetation in the Great Lakes (Figure 10). Typha generally ranges in height from 1 to $3 \mathrm{~m}$, while Phragmites can reach heights of more than 3.5 meters. Further, Phragmites forms tall, dense rather impenetrable stands. It is the sensitivity of L-band SAR to these differences in biomass and hydrology that allows the distinction between stands dominated by these two species.

Multi-date composites of PALSAR imagery from 2006-8 show the dynamic changes in the various vegetation cover-types over the growing season (Figure 11). In the top composite of Figure 11, which is a false color multi-date L-HH representation, the Typha are yellow to orange, indicating there is a strong return signal in July and October, but low response in the spring (Table 5). In contrast, most of the Phragmites shows a high response in the spring and lower in the summer and fall with shades of blue, and purple. In comparison, in the lower image of the L-HV multi-date false color composite (L-HV is sensitive to biomass), the Phragmites is cyan, indicating a strong return in the spring, April and May images, while the Typha is dark in these months, and bright (red) in the fall image. 


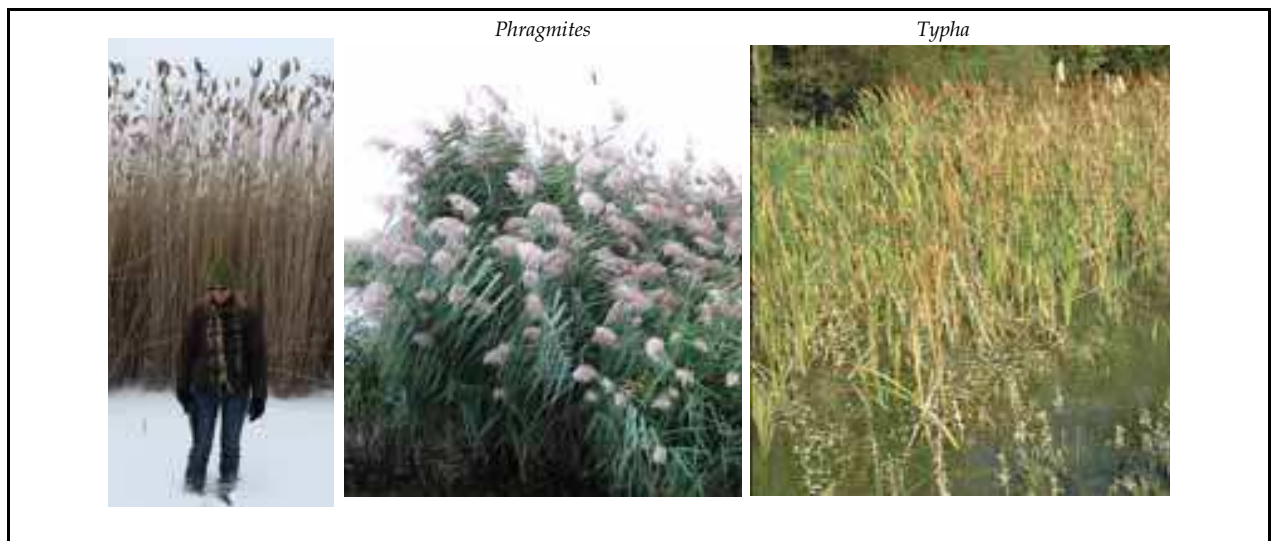

Fig. 10. Photos of Phragmites: tall scale in winter (left), high density in summer (middle), and typical Typha (right).

While either L-HH or L-HV multi-date imagery appear to be useful for distinguishing Phragmites from Typha, there are some stands that would be confused with the L-HV alone (see arrows with Phragmites label on Figure 11); these are areas of Phragmites that are red in the lower image and green in the upper image. The different signatures in the PALSAR imagery from Phragmites-dominated stands is likely due to differences in water levels in the various seasons. "Phragmites 2 " stands are located in diked areas, and may be wetter and sparser than "Phragmites 1" stands (Table 5).

\begin{tabular}{|l|l|l|l|l|}
\hline $\begin{array}{c}\text { PALSAR } \\
\text { Band }\end{array}$ & \multicolumn{1}{|c|}{ Image Date } & $\begin{array}{c}\text { Phragmites 1 } \\
\text { appearance }\end{array}$ & $\begin{array}{c}\text { Phragmites 2 } \\
\text { appearance }\end{array}$ & $\begin{array}{c}\text { Typha } \\
\text { appearance }\end{array}$ \\
\hline L-HH & 28 July 2006 & dark & dark & bright \\
\hline L-HH & 09 October 2007 & dark & bright & bright \\
\hline L-HH & 17 April 2008 & bright & dark & dark \\
\hline L-HV & 09 October 2007 & dark & bright & bright \\
\hline L-HV & 26 May 2008 & bright & dark & dark \\
\hline L-HV & 17 April 2008 & bright & dark & dark \\
\hline
\end{tabular}

Table 5. Appearance of two different Phragmites dominated stands versus Typha stands in the L-HH and L-HV imagery on the various dates.

\subsubsection{Mapping Phragmites with SAR}

A simple unsupervised maximum likelihood classification of the four dates of PALSAR data resulted in four classes of potential Phragmites and two potential classes of Typha spp. Note that the July 2006 image was from the single channel mode of ALOS PALSAR and thus had only the L-HH channel, analysis was therefore conducted on an input of 7 channels. Field observations using a GPS positioning system, in situ photos, and field notes were used to assess the preliminary "potential Phragmites" map. Using these field data for validation (29 points), the PALSAR multi-date preliminary map had $92 \%$ overall accuracy, with $100 \%$ 


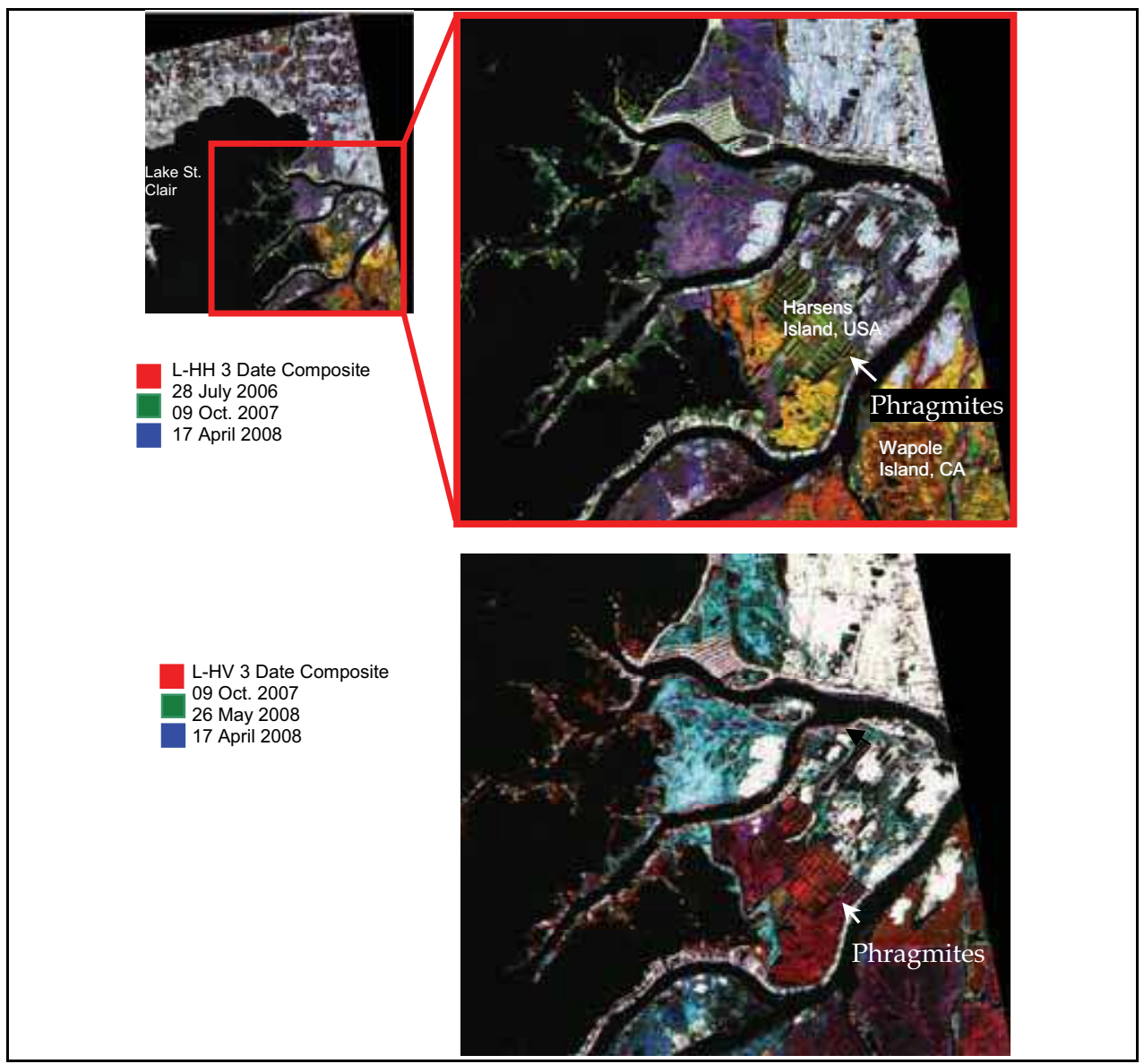

Fig. 11. False color composites of PALSAR imagery over Lake St. Clair delta. Top is L-HH from 28 July 2006 in red, 09 October 2007 in green and 17 April 2008 in blue. Bottom is L-HV composite with 09 October 2007 image in red, 26 May 2008 in green and 17 April 2008 in blue.

user's and $80 \%$ producer's accuracy for Typha, and 82\% producer's and 100\% user's accuracy for Phragmites. Note that the misclassified pixels for Phragmites were small areas of shrub or Typha within a larger Phragmites dominated area, thus the error is likely due to resolution ( $20 \mathrm{~m}$ in this case). The utility of the $10 \mathrm{~m}$ resolution PALSAR product (although only L-HH) may resolve this error and is being investigated.

\subsubsection{Mapping Phragmites with AVIRIS}

A comparison of the Optical/IR spectral signatures of Typha latifolia and Phragmites australis are shown in Figure 12. These signatures were collected in the field using a spectroradiometer (FieldSpec $3 \mathrm{JR}$ ). The vast differences in these signatures indicate that separation using Optical/IR remote sensing should be fairly easy, however, using the spectral angle mapper technique the results were poorer than the SAR methods. 


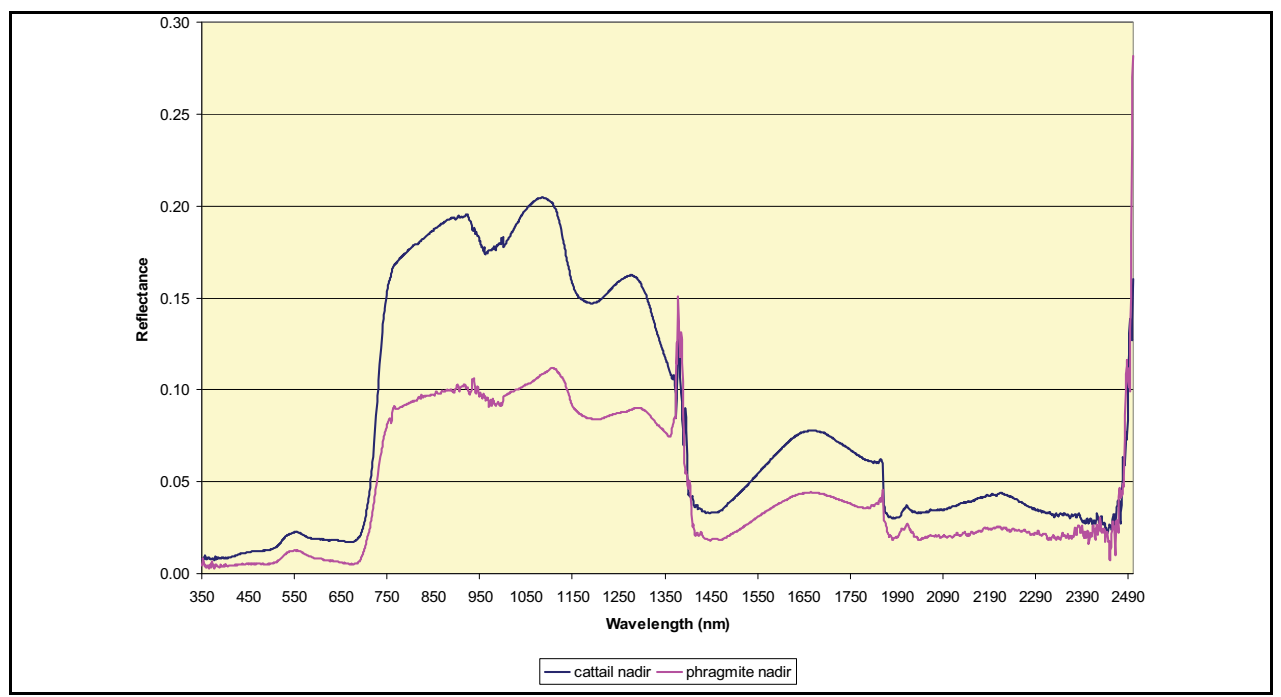

Fig. 12. Spectral signature comparison of Typha latifolia (black) versus Phragmites australis (red).

Spectral angle mapping is a physically-based spectral classification that uses n-dimensional ( $n=$ number of bands) angles to match pixels to reference spectra. It was run in ENVI, and determines similarity between the two spectra by calculating the angle and treating them as vectors in n-dimensional space. Smaller angles represent closer matches to the reference spectrum. The endmember spectra for Phragmites australis and Typha spp. used by the classifier were derived from field truth data provided by Michigan Natural Features Inventory.

Using methods similar to Lopez (2006), the spectral angle mapping of the 224 band (400$2500 \mathrm{~nm}$ ), $17 \mathrm{~m}$ resolution AVIRIS data using field training data, resulted in $82 \%$ overall accuracy with $83 \%$ user's and $77 \%$ producer's accuracy for Typha, but only $57 \%$ user's and $67 \%$ producer's accuracy for Phragmites. Note that the validation is based on only 17 points, because many of the points were used in the training

These are preliminary results and the investigation is ongoing. Methods are being investigated to determine the best bands from AVIRIS to combine with the L-band SAR for a data fusion approach. Evaluations will reveal the utility of SAR alone and in combination with hyperspectral, but the goal is to also determine if any of the bands of existing satellite Optical/IR systems could be used in lieu of hyperspectral data.

\subsection{Case Study: Peatland mapping in Alberta}

The last case study is based on the need to understand carbon storage (peat accumulation) and loss (mainly through fire) in boreal peatlands, which are widely recognized as being one of the largest terrestrial reservoirs for carbon (C) in the Northern Hemisphere. Estimating carbon storage and release requires an accurate mapping of peatland type. Peatlands are defined as wetlands with well developed peat (partially decayed plant matter) 
accumulation, generally more than $30 \mathrm{~cm}$ deep (Charman 2002). Peatlands actually represent diverse ecosystem types that differ in hydrology and vegetation, from forested rain-fed bogs to grass-dominated, saturated, or near-saturated stream-fed fens.

Early research on the ability to map boreal peatlands at a regional scale demonstrated the utility of merging SAR and Optical/IR data. Early observations included JERS, R-1, and Landsat imagery. Figure 13 presents Landsat and JERS images in comparison to a detailed peatland map (based on air photo interpretation and intensive field truth circa 1970-80s) with open, forested, and wooded categories of bogs, fens and swamps delineated. This preliminary analysis showed that Landsat would be useful for finding many of the open fens (see linear features circled in yellow; Figure 13). Whereas wooded fens do not look different from bogs in the Landsat image, they can be distinguished in the JERS SAR multidate imagery (see features circled in pink; Figure 13). Note that the majority of peatlands in this study region are wooded bogs (salmon color in the peatland map). The linear open fens are dark in the SAR similar to the open swamps and marshes. Here, C-band Radarsat should prove useful in distinguishing types of open peatlands. The complementary information obtained from the spectral reflectance properties of the vegetation combined with the structural and moisture information from SAR should allow the mapping of both peatland type (bog, fen, swamp) and level of biomass (open, sparse tree cover, forested).

\subsubsection{Remote Sensing Data}

Two dates of PALSAR imagery were obtained over the local Alberta study area from July and August of 2007. The dual-polarization PALSAR data included two channels, L-HH and L-HV. To complement this, a spring and summer data set of Landsat TM imagery were also obtained from April and August of 2001. Lastly we obtained two R-I images from July 1997 and 2005. These areas are so remote and vegetation growth is slow enough, that a 6-10 year difference in data collection is not problematic. The only large changes between the years would be wildfires, but we obtained all data on location and extent of wildfire from the Canada Forest Service for the time period of study and no fires occurred within the study area during that time.

\subsubsection{Image Interpretation}

Figure 14 shows two false color composites, one from the two dates of L-HV data from PALSAR and the other from two dates of L-HH data, with the first date as red and the second as cyan. These composites show how the cyan colored areas help distinguish fen from bog in the L-HH composite (bottom figure), since fens are characterized by fluctuating water levels and flowing water, whereas bogs tend to have water levels that remain below the moss covered surface with small changes in the short time period of the two image dates (July and August 2007). The L-HV cross polarized data provide information on the level of biomass which is essential in discrimination of low herbaceous open fens versus fen woodlands and open, wooded and forested bogs. This channel also clearly distinguishes the high biomass upland areas from the lowlands (Figure 14). Further, by using multi-date data, the seasonal changes in moisture and water levels are useful for discrimination of wetlands that generally have large changes in moisture/flood conditions (stream-fed fens) versus those that have smaller changes (rain-fed bogs). 
While most boreal peatlands in central Alberta are characterized by low canopy closure, allowing C-band R-1 to be useful, evaluation of the L-band JERS and PALSAR data demonstrate the additional definition of forests from ecosystems with low amounts of aboveground biomass and varying surface wetness conditions. While C-HH R-1 provides information on low aboveground biomass wetland types, JERS L-HH and PALSAR more clearly define the differences between forested wetland types, as well as distinguishing high and low aboveground biomass areas. The R-1 data were included in the mapping methods for distinguishing swamps since Grenier et al. (2007) found R-1 useful for such purposes.

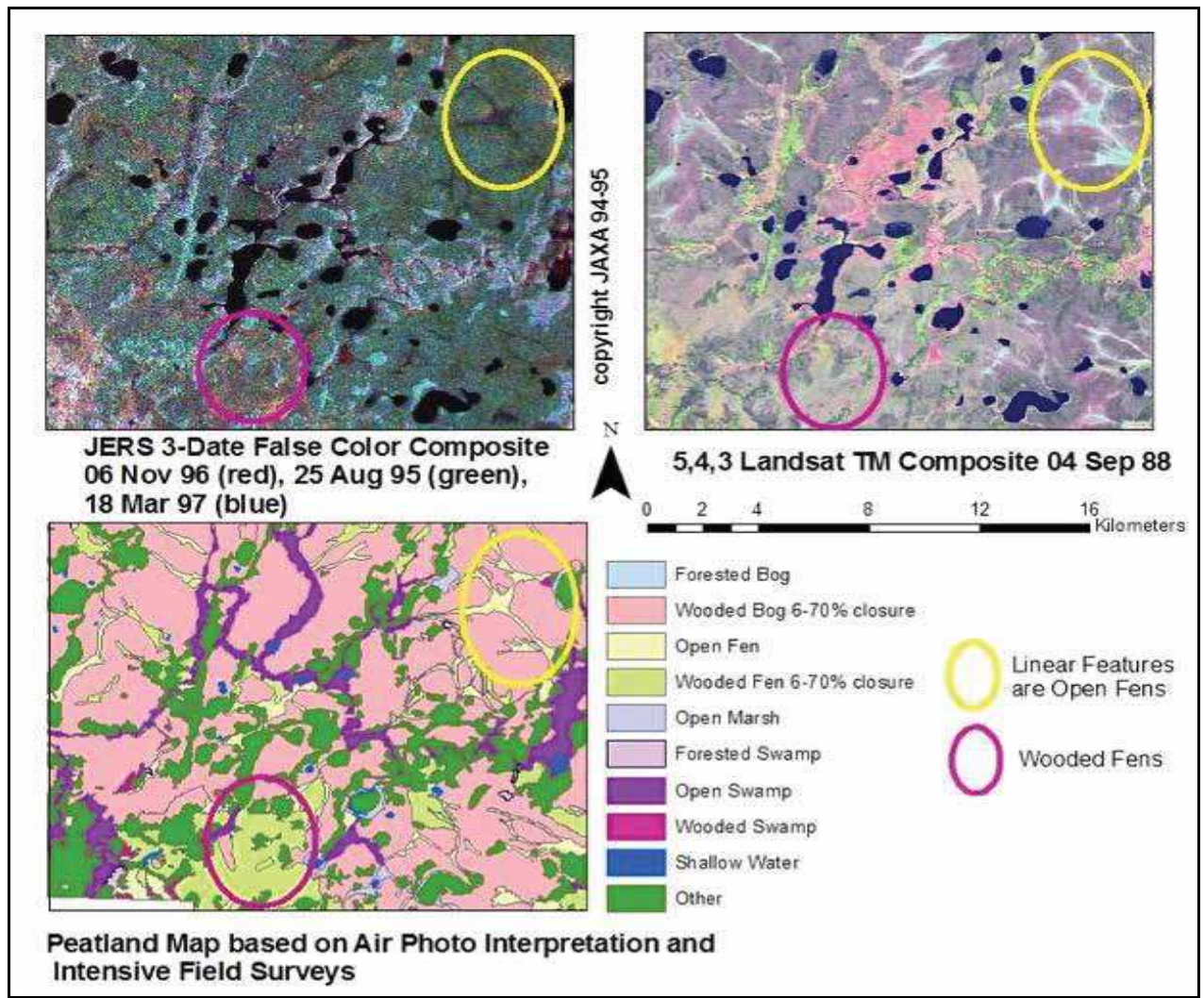

Fig. 13. Comparison of how different wetland types (bottom left, wetland map based on air photo and field truth) appear in 3 date JERS L-band imagery (1995-7, top left) versus Landsat imagery (Sept 88, top right). The pink circled areas are wooded fens and the yellow circled features are open fens. Most of the area in these scenes is wooded bog. 


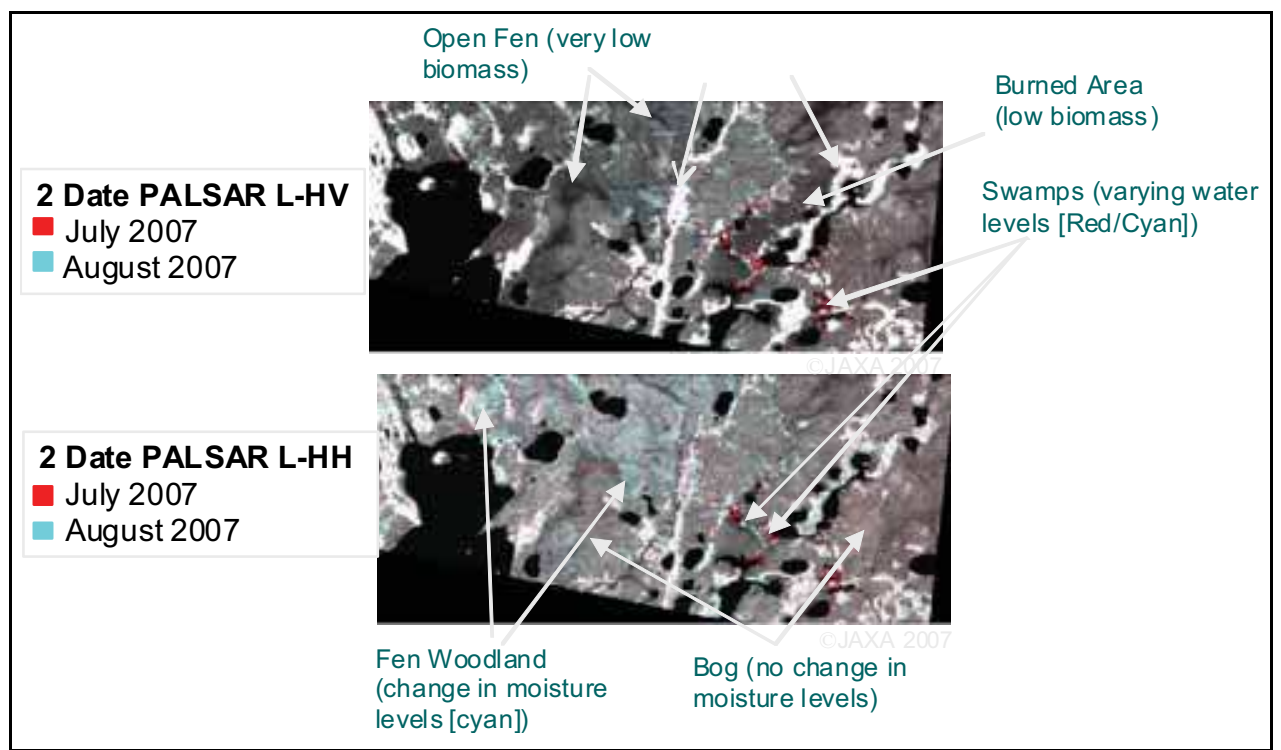

Fig. 14. Two date false color composites of PALSAR L-HV (top) and PALSAR L-HH (bottom) from July (red) and August (cyan) of 2007.

\subsubsection{Mapping Methodology}

Unlike the methodology used in the Great Lakes case study, here all data (SAR and Optical/IR) were fused in an object-based GIS analysis, using Definiens Professional software. Note, however, that Definiens Professional allows the user to choose which bands are used for each category being mapped. Thus, only Landsat may be used for one category, while only SAR is used for a second, and all data are used for a third, etc.

Object-based classification methods involve two phases: 1) spatial objects are formed using a region-growing segmentation algorithm to merge homogeneous pixels; and then 2) image classification techniques are applied. The segmentation phase provides additional attributes describing the spatial context and morphology of features which can inform the classification beyond spectral values alone. Segmentation can also be reiterated at various scales to capture the range of features contained in the image. This allows heterogeneous cover types (i.e., wetlands containing some open water pixels for example mixed with denser canopy) to be grouped depending on the segmentation scale chosen by the operator, and can significantly improve map accuracy (Grenier et al. 2007).

We first created segmentation regions defined by the Landsat and SAR. Then using data from April and August Landsat, two dates of PALSAR L-HV and L-HH and two dates of R$1 \mathrm{C}-\mathrm{HH}$, we developed a top-down classification approach in Definiens. The methodology relied on a combination of thresholds and nearest neighbor classifiers in a decision tree.

Using decision rules, we first distinguished land from open water using PALSAR L-HH and TM band 5 thresholds to map open water, with all non-water pixels being classified as land 
(Figure 15). Next the land was divided into burn and non-burn categories using a nearest neighbor classification of the Landsat data. Note that these burns occurred after the detailed Airphoto peatland map of Figure 13 was created, which we rely on as reference in our validation. Non-burned areas were then divided into upland versus wetland, with upland forest classified using PALSAR L-HV and TM band 3 from August 2001. Next the wetland classes were mapped. First open fen was mapped using L-HV and Landsat TM. Finally, a nearest neighbor classification was conducted on the remaining classes: Woodland Bog, Wooded Fen, and Swamp using April TM 3, 4, 5 and two dates of PALSAR HH, and two dates of R-1. Figure 15 shows the process, with the final map in Figure 16.

The final peatland map had $80 \%$ (Table 5) overall accuracy compared to the air-photo based map (circa 1970-80s photos), which was created from pre-burn photos (Bourgeau-Chavez et al., in prep.). The bog had $77 \%$ user's and $91 \%$ producer's accuracy, fen had $60 \%$ user's and producer's accuracy, upland had $88 \%$ user's and $76 \%$ producer's accuracy. Note that in the air photo-based reference map, both upland forest and open water were mapped as a merged class, and this is likely causing some error. Also, the time difference between the reference 70-80's air photo map and the SAR-optical map of 2000's likely resulted in changes to the landscape, notably the fires that occurred in 1988 and 1998. Also, fens are very difficult to map on air photos and there may be errors in the reference maps. We did find errors in some areas mapped as Marsh in the air photo-based map.

\subsubsection{Summary}

This initial research demonstrates the strong potential of a SAR-Optical/IR approach for application to large areas for a better understanding of the spatial variation in peatland types across the boreal landscape. Similar data fusion methods have been ( $\mathrm{Li}$ and $\mathrm{Chen}$ 2005) or are being used (Fournier et al. 2007, Grenier et al. 2007) for mapping peatlands of Canada. The CWI methods were described earlier (Grenier et al. 2007), but are much coarser classes. Li and Chen (2005) mapped peatlands of eastern Canada into open versus treed bog, marsh, swamp and open fen with high accuracy. Their methods involved the use of several dates of R-1 data ( $45^{\circ}$ incidence), Landsat and a DEM. While we found R-1 to be of limited use (as did Grenier et al. 2007) in western Canada, it should be noted that eastern Canadian peatlands are quite different than western peatlands, and the various methods will need to be assessed for transferability.

We are currently processing imagery to increase the Alberta study area to include a three scene mosaic of PALSAR from the two dates, using current Landsat from spring, summer, and fall, and ERS data. ERS data are being used over Radarsat, because of coverage of the larger area. Field visits are planned to areas in disagreement between the air photo map and SAR-Optical/IR map for validation and improvement of the mapping approach. Additional peatland study sites will also be evaluated in eastern Canada, and Alaska, as well as the Upper Peninsula of Michigan. 


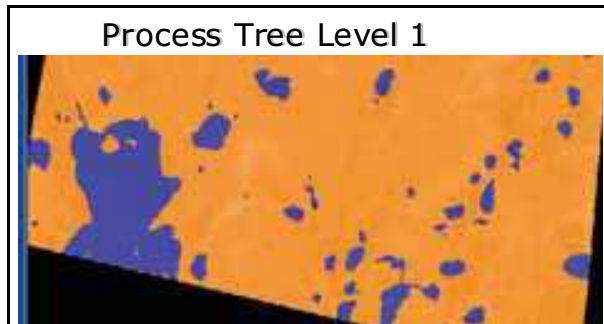

Orange $=$ land, Blue $=$ water

Process Tree Level 3

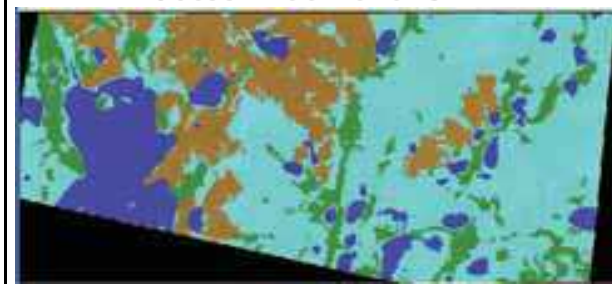

Process Tree Level 2

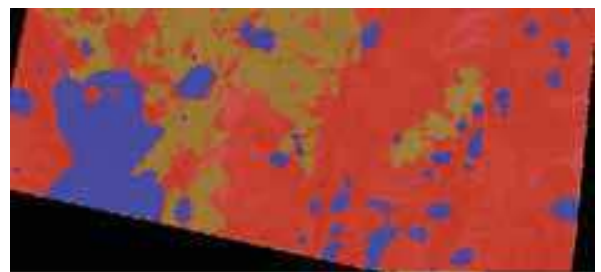

Brown = burn, Red $=$ unburn, blue $=$ water

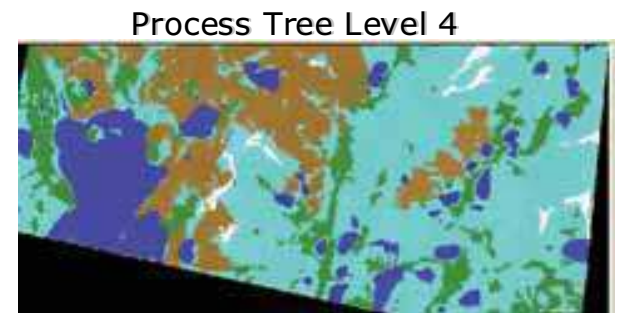

Brown $=$ burn, Green $=$ upland, Cyan $=$ wetland, blue $=$ water, white $=$ open fen

Figure 15. Process Tree images from the top down approach used for mapping Peatlands in the Central Alberta study area using Definiens.

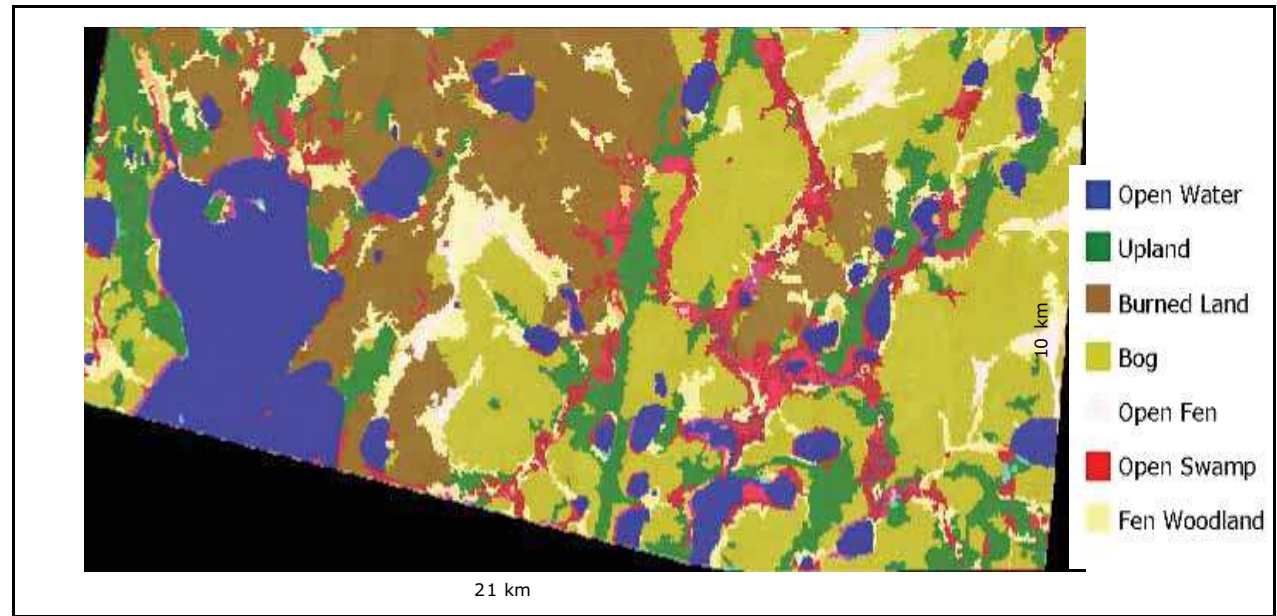

Figure 16. Hybrid SAR-optical derived map of Peatland types in central Alberta. 


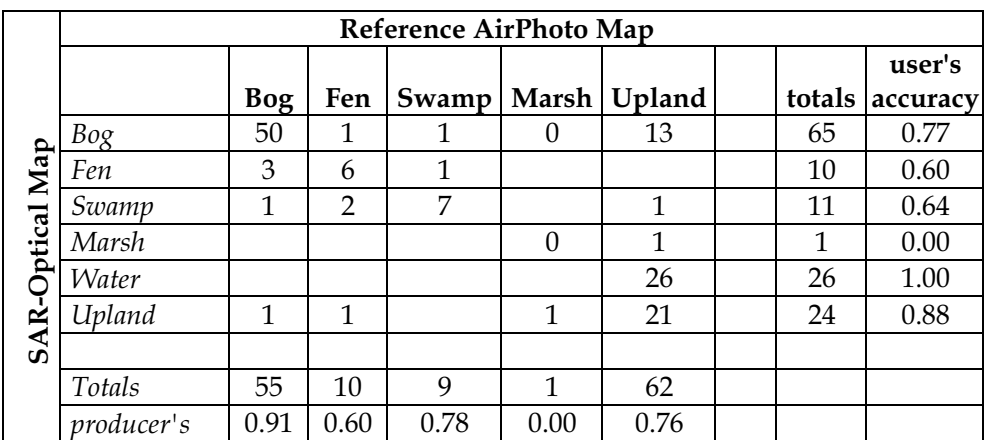

Table 5. Accuracy assessment of SAR-Optical Map on vertical axis and Airphoto map as reference (top). Note that Upland on the airphoto map was labeled " $Z$ " and represented open water and upland forest.

\section{Discussion and conclusions}

Many techniques focus on using multispectral data, such as Landsat or Aster, alone or in combination with ancillary data sets such as soils and topography for wetland mapping. However, research has shown how SAR and multispectral sensors complement each other in the classification and monitoring of wetland ecosystems and that SAR represents one of the most promising sensor types for improving wetland mapping capability (BourgeauChavez 2004, 2008, Grenier 2007, etc). While multispectral data measure spectral reflectance and emittance characteristics of various cover types and wetness in open canopied ecosystems, SAR is sensitive to variations in biomass, structure and soil moisture and flood condition of landscapes including forests and other closed canopy ecosystems. Forested wetlands are the most difficult to identify remotely because of the inability of traditional multispectral sensors to detect moisture beneath the canopy. Radar can not only penetrate a closed canopy to detect flooding, but since radars are active systems, can acquire data independently of solar illumination and cloud cover conditions. Thus, data can be collected during specific conditions relevant to finding seasonally flooded wetlands or seicheinfluenced wetlands. These SAR data can be used not only to detect and define wetlands, but also to monitor extent of inundation and in some cases level of inundation (BourgeauChavez et al. 2005, Lang et al. 2008).

The case studies shown here demonstrate the improved mapping capabilities by including SAR in the traditional Optical/IR methods of mapping. It is important to note that the timing of the acquisitions can be very important for detection of flooding beneath a canopy, as was seen in the two JERS dates of imagery over Lake. St. Clair, where neither image date was able to be used from mapping the flood condition. Further, the importance of multitemporal data was demonstrated in the image interpretation for all study sites, but particularly for the Canadian peatland study in which the subtle changes in backscatter due to changes in moisture levels allowed the distinction of wooded fens from bogs. Using knowledge of the phenological changes which occur in one wetland over another, as long as they are changes that can be detected by a particular sensor, can be key in distinguishing otherwise similar appearing ecosystems in the mapping process. 
While the results shown here focus on amplitude data from SAR, the new era of SAR sensors have full polarimetric capability and as such, polarimetric decomposition can be used to understand the type of scattering occurring from a particular ecosystem. Decomposition variables can be used alone, or as additional bands in the more typical multiband classifiers. Variables such as phase difference, which were used in the past have been further developed to include complex analysis of the full scattering matrix. Decomposition methods are being developed to use Radsarsat-2 for peatland discrimination using a single date of imagery (Touzi et al. 2007). These new techniques are in the early stages of development and have not been tested on a variety of sites yet. But there is great potential for these new polarimetric satellite sensors, which are just beginning to be explored.

\section{Acknowledgements}

This research was funded by the Great Lakes Coastal Wetlands Consortium, NASA and the U.S. Fish and Wildlife Service. Special thanks to Brian Benscoter and Merritt Turetsky for their assistance with the "truth" maps of Alberta peatlands.

\section{References}

Arzandeh, S. and J. Wang. 2002. Texture evaluation of RADARSAT imagery for wetland mapping. Can. J. Remote Sensing, 28(5):653-666.

Arzandeh, S. and J. Wang. 2003. Monitoring the change of Phragmites distribution using satellite data. Can. J. Remote Sensing. (29(1):224-35.

Augustein, M. and C. Warrender. 1998. Wetland classification using optical and radar data and neural network classification. Int. J. Rem. Sens. Vol. 19:1545-1560.

Baghdadi, N., M. Bernier, R. Gauthier, and I. Neeson. 2001. Evaluation of C-band SAR data for wetlands mapping. Int. J. Rem. Sens. Vol. 22:71-88.

Becker B., Lusch D., \& Qi J., (2005) Identifying optimal spectral bands from in-situ measurements of Great Lakes coastal wetlands using second derivative analysis. Remote Sens. Environ. 97 238-248.

Bourgeau-Chavez, L.L., M.R. Turetsky, B.W. Benscoter, and E.S. Kasischke. Improving mapping of boreal peatlands through use of Landsat and satellite SAR imagery, in prep.

Bourgeau-Chavez, L.L. and Richard Powell. 2009. Mapping the Invasive Phragmites with ALOS PALSAR radar imagery over the Saint Clair River Delta in the Great Lakes. Society of Wetland Scientists 2009 Conference, Madison, WI. June 21-26, 2009.

Bourgeau-Chavez, L.L., R.D. Lopez, A. Trebitz, T. Hollenhorst, G. E. Host, B. Huberty, R. L. Gauthier, and J. Hummer. 2008. Chapter 8, Landscape-Based Indicators in Great Lakes Coastal Wetlands Monitoring Plan, Great Lakes Coastal Wetlands Consortium, Project of the Great Lakes Commission, funded by the U.S. EPA GLNPO, March 2008, pp. 143-171. http://www.glc.org/wetlands/final-report.html

Bourgeau-Chavez, L.L., K.B. Smith, Eric S. Kasischke, S. M. Brunzell, E. A.

Romanowicz, and C. J. Richardson. 2005. Remote Monitoring Regional Scale Inundation Patterns and Hydroperiod in the Greater Everglades Ecosystem. Wetlands, Vol. 25(1):176-191.

Bourgeau-Chavez, L.L., K.Riordan, M. Nowels, and N. Miller. 2004. Final Report to the Great Lakes Commission: Remotely Monitoring Great Lakes Coastal Wetlands 
using a Hybrid Radar and Multi-spectral Sensor Approach. Project no. WETLANDS2-WPA-06.82pp.

http://www.glc.org/wetlands/pdf/GD-landscapeReport.pdf

Bourgeau-Chavez, L.L., E.S. Kasischke, S.M. Brunzell, J.P. Mudd, K.B. Smith, and A.L. Frick 2001. Analysis of spaceborne SAR data for wetland mapping in Virginia riparian ecosystems. Int. J. Rem. Sens, Vol. 22(18):3665-3687.

Charman, D. 2002. Peatlands and environmental change. J. Wiley \& Sons, London \& New York, $301 \mathrm{p}$.

Costa, M. , E. Novo, E. Ahern, E. Mitsou, J. Mantovani, M. Ballester, and R. Pietsch. 1998. The Amazon flood plain through Radar eyes: Lago Grande de Monte Alegre case study. Can. J. Remote Sensing. Vol. 24: 339-349.

Crawford, M., S. Kumar, M. Ricard, J. Gibeaut, and A. Neuenschwander. 1999. Fusion of airborne polarimetric and interferometric ASAR for classification of coastal environments. IEEE Trans. on Geosci. and Rem. Sens., Vol. 37:1306-1315.

Fournier, R. M. Grenier, A. Lavoie, R. Helie.. 2007. Towards a strategy to implement the Canadian Wetland Inventory using satellite remote sensing. Can. J. Remote Sensing. Vol. 33: 528-545.

Grenier, M., Demers, A.-M., Labrecque, S., Benoit, M., Fournier, R.A., and Drolet, B. 2007. An object-based method to map wetland using RADARSAT-1 and Landsat-ETM images:test case on two sites in Quebec, Canada. Can. J. Remote Sensing, Vol. 33:528-545.

Henderson, F. M., and A.J. Lewis. 2008. Radar detection of wetland ecosystems: a review. Int. J. Rem. Sens. Vol. 29(20):5809-1835.

Hess, L.L., J.M.Melack, S. Filoso, and Y. Wang. 1995. IEEE Trans. on Geosci. and Rem. Sens., 33(4)896-904.

Hess, L., J. Melack, and D. Simonett. 1990. Radar detection of flooding beneath the forest canopy: a review. Int. J. Rem. Sens. Vol. 11: 1313-1325.

IPCC 2008. Climate Change and Water, Intergovernmental Panel on Climate Change Technical Paper VI, ed. by B. Bates, Z.W. Kundzewicz, S. Wu, and J. Palutikof. June 2008.

Jensen, John R., 2007, Remote Sensing of the Environment: An Earth Resource Perspective, 2nd Ed., Upper Saddle River, NJ: Prentice Hall.

Kasischke, E.S., Smith, K.B., L.L. Bourgeau-Chavez,, E.A. Romanowicz, S. Brunzell, and C.J. Richardson. 2003. Effects of Seasonal Hydrologic Patterns in South Florida Wetlands on Radar Backscatter Measured from ERS-2 SAR Imagery. Rem. Sens. of Env. Vol. 88:423-441.

Kasischke, E.S. and L.L. Bourgeau-Chavez. 1997. Monitoring south Florida wetlands using ERS-1 SAR imagery. PE\&RS, Vol. 63(3): pp. 281-291.

Klemas, V.V., Dobson, J.E., Ferguson, R.L. and Haddad, K.D. 1993. A coastal land cover classification system for the NOAA Coastwatch

Change Analysis Project. Journal of Coastal Research, Vol. 9(3): 862-872.Li, J. and W. Chen. 2005. A rule-based method for mapping Canada's wetlands using optical, radar, and DEM data. Int. J. Rem. Sens. Vol. 26:5051-5069.

Lopez, R.D. D. T. Heggem, D. Sutton, T. Ehli, R. Van Remortel, E. Evanson, and L. Bice. 2006 Using Landscape Metrics to develop indicators of great lakes coastal wetland condition. US EPA Report EOA/600/X-06/002. www.epa.gov 77 pp. 
Lozano-Garcia, D.F., and R.M. Hoffer, 1993, Synergistic effects of combined Landsat-TM and SIR-B data for forest resources assessment. Int. J. Rem.Sens. Vol. 14(14), 2677.

Ozesmi, S. L., \& Bauer, M. E. (2002). Satellite remote sensing of wetlands. Wetlands Ecology and Management, 10(5), 381-402.

Pengra, B. C. Johnston, and T. Loveland. 2007 Mapping an invasive plant, Phragmites australis, in coastal wetlands using the EO-1 Hyperion hyperspectral sensor. Rem Sen Env, 108:74-81.

Peters, D. 1994. Use of aerial photography for mapping wetlands in the United States:

National Wetlands Inventory. Proceedings of the First International Airborne Remote Sensing Conference and Exhibition held in Strasbourg, France on 11-15 September, 1994 (Ann Arbor: ERIM) pp. 165-173.

Pope, K., E. Reimankova, J. Paris, and R. Woodruff. 1997. Detecting seasonal flooding cycles in marshes of the Yucatan peninsula with SIR-C polarimetric radar imagery. Rem. Sens. of Env. , Vol. 59:157-166.

Pope, K., J. Rey-Benayas, and J. Paris. 1994. Radar remote sensing of forest and wetland ecosystems in the Central American tropics. Rem. Sens. of Env. , Vol. 48:205-219.

Ramsey, E. III. 1998. Radar remote sensing of wetlands. Remote Sensing Change Detection: Environmental Monitoring Methods and Applications, R. Lunetta and C. Elvidge (eds) Chapter 13, pp. 211-243 (Chelsea, MI: Ann Arbor Press).

Rao, B., R. Dwivedi, S. Kushwaha, S. Bhattacharya, J. Anand, and S. Dasgupta. 1999. Monitoring the spatial extent of coastal wetlands using ERS-1 SAR data. Int. J. Rem. Sens., Vol. 20:2509-2517.

Rio, J. And D. Lozano-Garcia. 2000. Spatial filtering of radar data (RADARSAT) for wetlands (brackish marshes) classification. Rem. Sens. Environ. Vol. 73:143-151.

Schmidt K. \& Skidmore A. (2003) Spectral discrimination of vegetation types in a coastal wetland. Rem. Sens. Environ. 85 92-108.

Touzi, R., A. Deschamps, and G. Rother. 2007. Wetland characterization using polarimetric RADARSAT-2 capability. Can. J. Remote Sensing. Vol 33(1):S56-S67.

Townsend, P. 2002. Relationships between forest structure and the detection of flood inundation in forested wetlands using C-band SAR. Int. J. Rem. Sens., Vol. 22:443-460.

Townsend, P.A. 2001. Mapping seasonal flooding in forested wetlands using multi-temporal Radarsat SAR. PE\&RS, Vol. 67(7):857-864.

Toyra, J. Pietroniro, A. and L. Martz. 2001. Multisensor hydrologica assessment of freshwater wetland. Rem. Sens. Environ, Vol. 75:162-173.

Wang, Y. 2004. Seasonal change in the extent of inundation on floodplains detected by JERS1 Synthetic Aperture Radar data. Int. J. Remote Sensing, 25(13):2497-2508.

Wang, Y. And F. Davis. 1997. Decomposition of polarimetric synthesic aperture radar backscatter from upland and flooded forests. Int. J. Rem. Sens. , Vol. 18:1319-1332.

Whitcomb, J. M. Moghaddam, K. McDonald, J. Kellndorfer, and E. Podest. 2009. Mapping vegetated wetlands of Alaska using L-band radar satellite imagery. Can. J. Remote Sensing, Vol. 35:54-72.

Wilcox, K.L., S. A. Petrie, L.A. Maynard and S.W. Meyer. 2003. Historical Distribution and Abundance of Phragmites australis at Long Point, Lake Erie, Ontario. Journal of Great Lakes Research, 29(4):664-680

Wilen, B. and Frayer, W. 1990. Status and trends of U.S. wetlands and deepwater habitats. Forest Ecology and Management 33/34:181-192. 
Advances in Geoscience and Remole Sensing

Advances in Geoscience and Remote Sensing

Edited by Gary Jedlovec

ISBN 978-953-307-005-6

Hard cover, 742 pages

Publisher InTech

Published online 01, October, 2009

Published in print edition October, 2009

Remote sensing is the acquisition of information of an object or phenomenon, by the use of either recording or real-time sensing device(s), that is not in physical or intimate contact with the object (such as by way of aircraft, spacecraft, satellite, buoy, or ship). In practice, remote sensing is the stand-off collection through the use of a variety of devices for gathering information on a given object or area. Human existence is dependent on our ability to understand, utilize, manage and maintain the environment we live in - Geoscience is the science that seeks to achieve these goals. This book is a collection of contributions from world-class scientists, engineers and educators engaged in the fields of geoscience and remote sensing.

\section{How to reference}

In order to correctly reference this scholarly work, feel free to copy and paste the following:

Laura L. Bourgeau-Chavez, Kevin Riordan, Richard B. Powell, Nicole Miller and Mitch Nowels (2009). Improving Wetland Characterization with Multi-Sensor, Multi-Temporal SAR and Optical/Infrared Data Fusion, Advances in Geoscience and Remote Sensing, Gary Jedlovec (Ed.), ISBN: 978-953-307-005-6, InTech, Available from: http://www.intechopen.com/books/advances-in-geoscience-and-remote-sensing/improvingwetland-characterization-with-multi-sensor-multi-temporal-sar-and-optical-infrared-data-fu

\section{INTECH}

open science | open minds

\section{InTech Europe}

University Campus STeP Ri

Slavka Krautzeka 83/A

51000 Rijeka, Croatia

Phone: +385 (51) 770447

Fax: +385 (51) 686166

www.intechopen.com

\section{InTech China}

Unit 405, Office Block, Hotel Equatorial Shanghai

No.65, Yan An Road (West), Shanghai, 200040, China 中国上海市延安西路65号上海国际贵都大饭店办公楼 405 单元

Phone: +86-21-62489820

Fax: +86-21-62489821 
(C) 2009 The Author(s). Licensee IntechOpen. This chapter is distributed under the terms of the Creative Commons Attribution-NonCommercial-ShareAlike-3.0 License, which permits use, distribution and reproduction for non-commercial purposes, provided the original is properly cited and derivative works building on this content are distributed under the same license. 